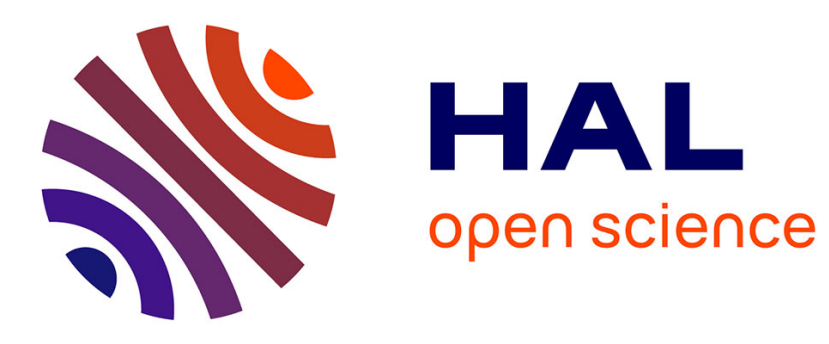

\title{
The iron-regulatory hormone hepcidin: A possible therapeutic target?
}

Luc Rochette, Aurélie Gudjoncik, Charles Guenancia, Marianne Zeller, Yves Cottin, Catherine Vergely

\section{- To cite this version:}

Luc Rochette, Aurélie Gudjoncik, Charles Guenancia, Marianne Zeller, Yves Cottin, et al.. The ironregulatory hormone hepcidin: A possible therapeutic target?. Pharmacology and Therapeutics, 2015, 146, pp.35-52. 10.1016/j.pharmthera.2014.09.004 . hal-03434150

\section{HAL Id: hal-03434150 \\ https://u-bourgogne.hal.science/hal-03434150}

Submitted on 18 Nov 2021

HAL is a multi-disciplinary open access archive for the deposit and dissemination of scientific research documents, whether they are published or not. The documents may come from teaching and research institutions in France or abroad, or from public or private research centers.
L'archive ouverte pluridisciplinaire HAL, est destinée au dépôt et à la diffusion de documents scientifiques de niveau recherche, publiés ou non, émanant des établissements d'enseignement et de recherche français ou étrangers, des laboratoires publics ou privés. 
The iron-regulatory hormone hepcidin: a possible therapeutic target?

Luc Rochette ${ }^{\mathrm{a} *}$, Aurélie Gudjoncik ${ }^{\mathrm{ab}}$, Charles Guenancia ${ }^{\mathrm{ab}}$, Marianne Zeller ${ }^{\mathrm{a}}$, Yves Cottin ${ }^{\mathrm{ab}}$, Catherine Vergely ${ }^{\mathrm{a}}$.

'abaratoire de Physiopathologie et Pharmacologie Cardio-Métaboliques (LPPCM) Inserm UMR866, Facultés de Médecine et de Pharmacie - Université de Bourgogne.

7 Bld Jeanne d'Arc 21033 DIJON France

${ }^{\mathrm{b}}$ Service de Cardiologie CHU Bocage DIJON France

*Corresponding author: Professor Luc Rochette Laboratoire de Physiopathologie et Pharmacologie Cardio-métaboliques (LPPCM) Inserm UMR866, Facultés de Médecine et de Pharmacie - Université de Bourgogne. DIJON, France.

Luc.rochette@u-bourgogne.fr 


\section{ABSTRACT}

The maintenance of stable extracellular and intracellular iron concentrations requires the coordinated regulation of iron transport into plasma. Iron is a fundamental cofactor for several enzymes involved in oxidation-reduction reactions. The redox ability of iron can lead to the production of oxygen free radicals, which can damage various cellular components. Therefore, the appropriate regulation of systemic iron homeostasis is decisive in vital processes. Hepcidin has emerged as the central regulatory molecule of systemic iron homeostasis. It is synthesized in hepatocytes and in other cells and released into the circulation. It inhibits the release of iron from enterocytes of the duodenum and from macrophages by binding to the iron exporter protein, ferroportin (FPN). FPN is a transmembrane protein responsible for iron export from cells into the plasma. Hepcidin is internalized with FPN and both are degraded in lysosomes. The hepcidin-FPN axis is the principal regulator of extracellular iron homeostasis in health and disease. Its manipulation via agonists and antagonists is an attractive and novel therapeutic strategy. Hepcidin agonists include compounds that mimic the activity of hepcidin and agents that increase the production of hepcidin by targeting hepcidin-regulatory molecules. The inhibition of hepcidin could be a potentially attractive therapeutic strategy in patients suffering from anaemia or chronic inflammation. In this review, we will summarize the role of hepcidin in iron homeostasis and its contribution to the pathophysiology of inflammation and iron disorders. We will examine emerging new strategies that modulate hepcidin metabolism. 


\section{Contents}

1. Introduction

2. Systemic iron metabolism and the importance of iron storage

3. Diseases associated with iron deficiency or iron overload

4. The liver: the main regulator of iron metabolism and producer of iron-regulatory proteins

5. Levels, structures, and kinetics of hepcidins

6. Sites of extra-hepatic hepcidin production

7. Importance of hepcidin-ferroportin interactions

8. Hepcidin: master regulator of iron metabolism

9. Regulation of hepcidin expression

10. Pharmacology: targeting the hepcidin-ferroportin axis

11. Hepcidin: an endogenous cytoprotective agent in cardiovascular pathophysiology?

12. Conclusion 


\section{Abbreviations:}

$A A$, amino-acid; $A B C A 1, A T P$ binding cassette transporter $A 1 ; A B C B$ : ATP-binding cassette $(A B C)$ transporter; AKI, acute kidney injury; $A M I$, acute myocardial infarction; ARE, antioxidant response element; ATP, adenosine triphosphate; CHD, coronary heart disease; CKD, chronic kidney disease; CHF, chronic heart failure; CO, carbon monoxide; COX, cyclooxygenase; $C P B$, cardiopulmonary bypass; $C R E B H$, cyclic AMP response element-binding protein-H; CRP, C-reactive protein; DMT1, divalent metal transporter 1; EAM, experimental autoimmune myocarditis; EPO, erythropoietin; ER, endoplasmic reticulum; ESAs, erythropoietin-stimulating agents; FPN, ferroportin; GDF-15, growth differentiation factor15; hHepc, human hepcidin; HIF, hypoxia-inducible factor; HJV, hemojuvelin; HMGB1, high mobility group protein $\mathrm{B} 1$; $\mathrm{HO}$, heme oxygenase; $\mathrm{H}_{2} \mathrm{~S}$, hydrogen sulphide; $\mathrm{HSP}$, heat shock protein; IL, interleukin; IREs, iron responsive elements; IRPs, iron regulatory proteins; JAK, Janus kinase; Keap, Kelch-like ECH-associated protein 1; LPS, lipopolysaccharide; Lrp1, lipoprotein receptor-related protein-1; $\alpha 2 \mathrm{M}$, a2-macroglobulin; MAL, MyD88 adapter-like; NO, nitric oxide; NOS, nitric oxide synthase; NOX, nicotinamide adenine dinucleotide phosphate oxidase; Nrf2, nuclear factor erythroid-related factor 2; PEG, polyethylene glycol; RNOS, reactive nitrogen and oxygen species; RNS, reactive nitrogen species; ROS, reactive oxygen species; sHJV.Fc, soluble HJV-Fc fusion protein; SOD, superoxide dismutase; STAT, signal transducer and activator of transcription; SR, sarcoplasmic reticulum; Tf, transferrin; TfR, Tf receptors; TLR, toll-like receptors; TPP, thiamine pyrophosphate; TRAM, TLR4-TRIFrelated adapter molecule; TTFD, thiamine tetrahydrofurfuryl disulphide. 


\section{Introduction}

Iron is a fundamental cofactor for several enzymes involved in oxidation-reduction reactions due to its ability to exist in two ionic forms: ferrous ( $\mathrm{Fe}+2)$ and ferric $(\mathrm{Fe}+3)$ iron. However, the redox ability of iron can lead to the production of oxygen free radicals, which can damage various cellular components. For this reason, iron levels in tissues must be tightly regulated (Ganz, 2013). Various molecules are involved in iron uptake and storage by hepatocytes and its export from hepatocytes, and systems describing the iron cycle have evolved. The discovery of the iron-regulating role of the hormone hepcidin, followed by the elucidation of its mechanism of action has led to better understanding of the physiopathology of human iron disorders (Munoz-Bravo, Gutierrez-Bedmar, GomezAracena, Garcia-Rodriguez, \& Navajas, 2013; Waldvogel-Abramowski, et al., 2014) and offers new clinical potential in terms of diagnosis and therapy. Hepcidin has emerged as the central regulatory molecule of systemic iron homeostasis. Knowledge on how hepcidin exerts its regulatory function and on the molecular processes that regulate hepcidin production is largely based on animal and in vitro studies. Hepcidin is a peptide secreted predominantly from hepatocytes. It down-regulates ferroportin, the only known iron exporter, and therefore inhibits iron efflux from duodenal enterocytes, macrophages and hepatocytes into the bloodstream (Ganz \& Nemeth, 2012). Hepcidin expression is regulated positively by body iron load. Although the underlying mechanism of ironregulated hepcidin expression has not been fully elucidated, several proteins have been identified that participate in this process. In this review, we will summarize the role of hepcidin in iron homeostasis and its contribution to the pathophysiology of inflammation and iron disorders. We will examine emerging new strategies to modulate hepcidin metabolism. The therapeutic manipulation of hepcidin activity may become an important approach in cardiovascular and metabolic disorders.

\section{Systemic iron metabolism and the importance of iron storage}

\subsection{Iron distribution}

The total amount of iron in a 70-kg adult is approximately $4 \mathrm{~g}$, of which two thirds is the iron in red blood cells and $300 \mathrm{mg}$ is in the myoglobin of muscles. The majority of this iron comes from the recycling of senescent erythrocytes by macrophages of the reticulo-endothelial system (about $20 \mathrm{mg} /$ day) (Table 2)(Gudjoncik, et al., 2014). Most of the iron in plasma is 
directed to the bone marrow for erythropoiesis. More than 2 million new erythrocytes are produced every second by the bone marrow, requiring a daily supply of at least 20-30 mg of iron. Only 1 to $2 \mathrm{mg}$ of the daily iron supply is derived from intestinal absorption, which, under a steady state, is sufficient only to replace insensible iron loss. Significant amounts of iron are also present in macrophages (up to $600 \mathrm{mg}$ ) whereas excess body iron ( $1 \mathrm{~g}$ ) is stored in the liver. Each erythrocyte contains a billion atoms of iron; at normal rates of turnover, this concentration corresponds to the incorporation of $2 \times 10^{20}$ atoms of iron per day. Consequently, anaemia is the cardinal sign of iron deficiency. The best characterized syndrome of iron overload is hereditary hemochromatosis (Vujic, 2014). The acquisition, transport, utilization and storage of iron are tightly controlled to meet physiological needs and prevent excessive accumulation of the metal within cells. Mammals utilize distinct mechanisms to regulate iron homeostasis at the systemic and cellular levels (Lawen \& Lane, 2013).

\subsection{Proteins that exert crucial functions in the maintenance of systemic iron homeostasis}

\subsubsection{A range of regulatory mechanisms: general regulation}

Several proteins, such as transferrin, ferritin, hemosiderin, hepcidin and ferroportin, exert crucial functions in the maintenance of systemic iron homeostasis. Macrophages play an important role in executing the regulatory events that lead to changes in systemic iron levels (Gammella, Buratti, Cairo, \& Recalcati, 2014). Schematically, the main site of iron absorption is the small intestine, but most iron is recycled by the monocyte-macrophage system via phagocytosis of senescent erythrocytes. In the circulation, iron is usually bound to transferrin (Tf), and most of the Tf-bound iron is utilized for bone marrow erythropoiesis (Gudjoncik, et al., 2014). Within cells, iron is stored in the proteins ferritin or hemosiderin. Iron is the only micronutrient known to have a regulatory hormone, hepcidin, which responds to both nutrient status and infections. Hepcidin is mainly synthesized in the liver. It is a negative regulator and its production is increased during iron overload and inflammation. Intracellular iron is released into the circulation via ferroportin (FPT). The iron is donated to Tf and reutilized for bone marrow erythropoiesis. Hepcidin binds to the iron exporter FPT and leads to its degradation, thereby inhibiting intestinal iron absorption, cellular export and reticulo-endothelial iron release (Munoz, Garcia-Erce, \& Remacha, 2011). 


\subsubsection{Role of Ferritin}

Multiple physiological processes are involved in maintaining iron homeostasis. These include iron storage at the intracellular and extracellular levels. Ferritin is the major iron-storage protein. Typical ferritins are composed of 24 subunits, which fold into a 4-helix bundle and form an almost spherical protein shell. There is a strong equilibrium between ferritin-bound iron $\left(\mathrm{Fe}^{3+}\right)$ and the labile iron pool in cells $\left(\mathrm{Fe}^{2+}\right)$, by which ferritin prevents the formation of reactive oxygen species mediated by the Fenton reaction (Alkhateeb \& Connor, 2013). Various cell types contain a transient cytosolic pool of iron, presumably bound to lowmolecular-mass intracellular chelates, such as citrate, various peptides, ATP, AMP or pyrophosphate. This labile iron pool is redox-active and its concentration is determined by the rates of iron uptake, utilization for incorporation into iron enzymes, storage in ferritin and export from the cell (Cabantchik, 2014).

There are two functionally and genetically distinct ferritin subunits: L-ferritin and H-ferritin (also known as light-chain and heavy-chain ferritin). Ferritin is found in the cytoplasm, nucleus and mitochondria of cells. Serum ferritin has been thought to reflect iron stores in the body and to increase as a secreted by-product of intracellular ferritin synthesis. Cellular iron is stored primarily in the cytoplasm, but organelles such as mitochondria are the main users of metabolically active iron (MacKenzie, Iwasaki, \& Tsuji, 2008).

The regulation of ferritin synthesis by iron is mainly due to post-transcriptional regulation through the binding of IRP1 and IRP2 to iron-responsive elements (IRE) located in the 5' UTR of ferritin mRNA. Both IRP1 and IRP2 are expressed ubiquitously in most tissues. In addition to iron-mediated regulation, oxidative stress is able to modulate the activity of IRP1 and IRP2. This process is regulated at the transcriptional level through an antioxidant-responsive element (ARE) (Tsuji, 2005). The role of nitric oxide (NO) in the regulation of the IRP/IRE system is well established (Hentze, Muckenthaler, \& Andrews, 2004). NO induces the expression of FPN, the transmembrane protein responsible for iron export from macrophages, and is associated with activating the transcription factor nuclear erythroid 2related factor-2 (Nrf2) (Nairz, et al., 2013). Given the established regulatory circuits between nitric oxide synthase (NOS) activity and iron homeostasis, it has been hypothesized that iron homeostasis and NO biology are interconnected. Recent studies showed that haemoglobin $\alpha$ haem iron in the oxygenated $\mathrm{Fe}^{2+}$ state and NOS are in a macromolecular complex and can form a direct protein-protein interaction (Straub, et al., 2012). 


\subsubsection{Role of Transferrin}

Cellular iron homeostasis is accompanied by the coordinated regulated expression of ferritin and other proteins including Tf. Cells have transferrin receptors (TfR) that mediate iron metabolism. Iron is imported through the endocytosis of $\mathrm{Fe}^{3+}$-loaded Tf that interacts with its TfRs (TfR1 and TfR2) in a tightly regulated feedback loop controlled at the genetic and protein level. Tf is a monomeric protein of $76-81 \mathrm{kDa}$ comprising two structurally similar lobes (termed $\mathrm{N}$-and $\mathrm{C}$-lobes), each of which contains a single iron-binding site. Plasma Tf is a powerful chelator, capable of binding iron tightly but reversibly. Iron chelation by Tf serves to maintain $\mathrm{Fe}^{3+}$ in a soluble form in a redox-inert state, thus preventing the generation of toxic free radicals (Gkouvatsos, Papanikolaou, \& Pantopoulos, 2012). TfR1 (also known as CD71) is ubiquitously expressed at low levels in most normal human tissues. TfR2 is a protein that is highly homologous to TfR1 but whose expression is largely restricted to hepatocytes. Serving as the main port of entry for iron bound Tf into cells, TfR1 is a type-II receptor that resides on the outer cell membrane. The Tf-TfR complex is internalized via clathrin-coated pits and then metabolized in the lysosome (Daniels, et al., 2012). Iron homeostasis is controlled by Tf as well as in other ways. In this context, a relationship exists between TfRs and peptides such as hepcidin, which appears to be involved in the final common pathway towards which the components of the regulatory network converge to control tissue iron metabolism.

A decade ago, hepcidin, an antimicrobial peptide with iron-regulatory properties, was discovered and found to play a significant role in iron regulation in health and disease. Hepcidin is predominantly synthesized in hepatocytes, secreted from hepatocytes and excreted through the kidney. In iron deficiency or in haemorrhagic or haemolytic anaemia, the production of hepcidin in hepatocytes decreases. When this happens, both iron absorption in the duodenum and the release of iron from stores are greatly increased. In patients with anaemia or chronic disease, hepcidin is over expressed (Polin, et al., 2013). In the following chapters of this review, we will describe the structures and functions of hepcidin and examine emerging new pharmacological strategies that modulate hepcidin metabolism. 


\section{Diseases associated with iron deficiency or iron overload}

\subsection{Iron deficiency}

The symptoms and signs of iron deficiency are partly explained by the presence of anaemia. Iron deficiency will result from any condition in which dietary iron intake does not meet the body's demands; for this reason, rapidly growing children and premenopausal women are at the highest risk. Iron deficiency caused by dietary insufficiency is usually secondary to intestinal blood loss. Congenital and acquired abnormalities of the intestinal epithelium can also result in iron deficiency. The combination of mild-to-moderate anaemia and hypoferraemia is often seen in chronic infections, inflammatory disorders, haematological malignancies, and some solid tumours. Inflammation anaemia has also been called the "anaemia of chronic disease," (Corwin \& Krantz, 2000). The influence of iron deficiency was underestimated especially in terms of worsening of cardiovascular diseases and of developing anaemia (Ebner \& von Haehling, 2013). Approximately one third of patients with congestive heart failure (CHF) and $10 \%$ to $20 \%$ of those with coronary heart disease (CHD) also have anaemia. Anaemia is associated with more symptoms, a greater hospitalization rate and increased mortality rates in patients with CHF and CHD (Kansagara, et al., 2013).

\subsection{Iron-overload: Hemochromatosis}

Iron-overload leads to excessive iron deposition in a wide variety of tissues. The rapid and massive influx of iron into the plasma can cause an early-onset organ disorder called juvenile hemochromatosis, which includes heart failure and endocrine insufficiency. Primary (hereditary) hemochromatosis and secondary iron overload (hemosiderosis) is reaching epidemic levels worldwide. In genetic hemochromatosis and in $\beta$-thalassemia, iron overload is the primary cause of liver cirrhosis, diabetes, and heart failure. Over $85 \%$ of all cases of hemochromatosis are due to mutations in the hemochromatosis protein, which is involved in iron metabolism. Human hemochromatosis protein also known as the HFE protein is a protein encoded by the HFE gene (Moyer, Highsmith, Smyrk, \& Gross, 2011). The cardiac and endocrine systems are particularly susceptible to rapid iron loading. In cells, iron induces an increase in oxidative stress and limits high-energy electron transport required for mitochondrial respiration (Murphy \& Oudit, 2010). Four meta-analyses of the studies examining the association between four HFE gene variants and the risk of coronary heart 
diseases were recently conducted. HFE gene mutations were shown to be associated with iron overload and cardiovascular diseases (Lian, et al., 2013).

The management of iron overload and the treatment of iron toxicity by chelation in patients with acquired iron overload (e.g. Transfusion-dependent anaemia) have been shown to reduce iron burden and improve survival. Iron chelators are best known for their ability to sequester iron from the cell or organism and to function as an antioxidant by preventing the Fenton reaction. Three iron chelating agents: Deferoxamine, Deferiprone and Deferasirox are currently available (Munoz, et al., 2011). Other orally active iron chelators are currently under development and one, FBS0701, is in a clinical trial. FBS0701 has been shown to bind $\mathrm{Fe}^{3+}$ with very high affinity and selectivity and has demonstrated a no-observable-adverseeffect level at least 4 times greater than that obtained with deferasirox suggesting a favourable clinical safety profile (Ma, Zhou, Kong, \& Hider, 2012; Neufeld, et al., 2012).

\section{The liver: the main regulator of iron metabolism and producer of iron-regulatory proteins (figure 1)}

The liver is the central regulator of systemic iron balance. Hepatocytes not only store iron, but also play a crucial role in iron metabolism by producing $\mathrm{Tf}$, the iron carrier protein, and hepcidin, a hormone involved in regulating iron metabolism. As we reported previously, hepcidin is mainly synthesized in hepatocytes, secreted from hepatocytes, and excreted through the kidney. Schematically, extracellular circulating iron in the plasma is present as soluble Tf-bound iron, and when there is excess iron, it binds to serum proteins or citric acid. Human serum albumin is known to be a low-affinity iron-binding protein and it has been proposed as a ligand for the non-transferrin-bound iron (NTBI) pool that exists in the sera of iron-overload patients. Hepatocytes express both TfR 1 and TfR2. TfR1 expression is controlled by the level of iron within cells, and is regulated by the iron regulatory proteins (IRP)- iron-responsive elements (IRE) regulatory system (Cairo \& Recalcati, 2007). $\mathrm{Fe}^{2+}-\mathrm{Tf}$ binds with TfR1 on the cell membrane surface to form a complex that, as mentioned above, is then transported into hepatocytes by endocytosis. The released ferrous iron is transported from the interior of the endosome to the cytosol by divalent metal transporter 1 (DMT1). A growing body of evidence suggests that dysregulation of iron metabolism contributes to age-related pathologies. Hepatocyte senescence correlated positively with hepatic iron concentrations, serum ferritin and oxidative stress. The mechanisms that contribute to iron 
retention with aging are unclear, but might involve enhanced iron uptake, or reduced iron export in these tissues, potentially resulting from the dysregulation of iron transport proteins (Wood, Gadd, Powell, Ramm, \& Clouston, 2014). Iron retention generates oxyradicals and contributes to the peroxidation of lipids and proteins in membranes, thus leading to cellular toxicity. This process is thought to contribute to hepatocellular necrosis and apoptosis and the development of hepatic fibrosis in pathologies associated with iron retention (Ramm \& Ruddell, 2010). The hypothesis according to which iron overload could be harmful has been extensively and controversially discussed in relationship with oxidative stress. In patients, the correlation between hemochromatosis and an established marker of oxidative stress, the urinary excretion of 8-iso-prostaglandin F2 $\alpha$ has been demonstrated (Kom, Schwedhelm, Nielsen, \& Boger, 2006). A recent study in rats investigated whether or not iron supplement facilitated the onset of induced type-2 diabetes by the overproduction of reactive oxygen species (ROS) and reactive nitrogen species (RNS) and exacerbated oxidative/nitrosative stress in association with hepatic dysfunction. Both diabetes and elevated amounts of liver iron caused hepatic disease, resulting in increased liver injury including fibrosis, inflammation and hepatocellular necrosis (Li, et al., 2012). These results were similar to the conclusions of studies in animal models of hemochromatosis (Klopfleisch \& Olias, 2012). It is known that mutations in HFE or TfR2 cause hereditary hemochromatosis by impeding production of the liver's iron-regulatory hormone, hepcidin. The effects of disrupting HFE or TfR2, either alone or together, on liver iron loading and injury in mouse models of hereditary hemochromatosis were investigated. Liver F2-isoprostane levels were higher, and copper/zinc and manganese superoxide dismutases (SODs) activities lower in mutant animals than in wild-type mice (Delima, et al., 2012). In conclusion, there is now strong evidence that iron overload plays an important role in the initiation and progression of hepatic injury through its ability to catalyse the formation of ROS thus inducing oxidative stress that is not compensated for by endogenous antioxidant mechanisms.

\section{Levels, structures, and kinetics of hepcidin}

\subsection{Levels of hepcidin}

Hepcidin was discovered by three laboratories working independently (Krause, et al., 2000; Park, Valore, Waring, \& Ganz, 2001; Pigeon, et al., 2001).The laboratory of Tomas Ganz invented the name hepcidin, because the gene is highly expressed in the liver (hep-) and was 
found to possess some microbicidal activity (-cidin). The bacteriostatic effects of iron-binding proteins had already been recognized in the 1940s. It was noted that specific iron-binding proteins in egg white (ovotransferrin) and blood (transferrin) inhibited the growth of certain bacteria-an effect easily reversed by adding iron. There are considerable differences in hepcidin levels depending on the method used to make the measurement. Absolute hepcidin concentrations differed widely between the assays (Laarakkers, et al., 2013).

To date, concentrations of the biomarker hepcidin have only been assessed in the sera of relatively small series of healthy volunteers and patients. In a large, well-phenotyped sample of the general population ( $\mathrm{n}=2998$ ), a recent study assessed age- and sex-stratified reference ranges of serum hepcidin concentrations. Variations in hepcidin concentrations over age differed between men and women. Men showed a stable hepcidin concentration, although a non-significant trend towards an age-related increase in serum hepcidin was previously reported in a study of 65 men. In women, serum hepcidin concentration was substantially higher for postmenopausal than for premenopausal women. The median serum hepcidin concentration in men was $7.8 \mathrm{nM}$, while that in women was $4.1 \mathrm{nM}$ for women younger than 55 years and $8.5 \mathrm{nM}$ for women aged 55 years and older (Galesloot, et al., 2011). There is currently no evidence to support either a primary or secondary circadian variation in hepcidin. However, circadian variations in hepcidin do exist and could be secondary to variations in iron intake during the day. Serum ferritin was shown to be the most important correlate of serum hepcidin concentration (Ashby, et al., 2009). In the Nijmegen Biomedical Study, hepcidin and the hepcidin/ferritin ratio, which reflects hepcidin expression relative to iron stores, were significantly associated with the presence of atherosclerotic plaque in postmenopausal women (Galesloot, et al., 2014). It has been hypothesized that high levels of hepcidin may increase cardiovascular risk by slowing or preventing the mobilization of iron from macrophages. (see later paragraph: Hepcidin: endogenous cytoprotective agent in cardiovascular pathophysiology and possible therapeutic targets).

\subsection{Structure of hepcidin (figure 2)}

Hepcidin is synthesized in the liver as an 84-amino-acid (AA) preprohormone, and is targeted to the secretion pathway by a 24-AA N-terminal targeting sequence. The resulting 60-AA pro-hepcidin is processed further into a mature C-terminal $25-\mathrm{AA}$ active peptide ( $2.7 \mathrm{kDa}$ ) 
that is secreted into the circulation. The human 25-amino-acid hepcidin peptide contains four disulphide bonds, and urinary hepcidin is rich in $\beta$-sheet. Hepcidin forms a simple hairpin stabilized by four disulphide bonds (Ganz, 2005). Under physiological conditions, $\mathrm{N}$-terminal truncated hepcidin-20, -22 and -24 peptides have been observed in the urine, but are absent from or exist at low concentrations in plasma. These smaller hepcidin isoforms mostly occur in plasma in diseases that are associated with significantly increased hepcidin concentrations, such as sepsis and kidney failure. Hepcidin concentrations were reported to be increased in patients with chronic kidney disease. This could be caused by inflammation, which frequently accompanies renal failure. However, even patients without significant inflammation have elevated hepcidin levels that progressively increase with the severity of the kidney disorder. Because hepcidin is cleared, at least partially, by filtration in the kidney, decreased kidney function probably contributes to this phenomenon. This hypothesis is supported by a number of studies that reported an inverse correlation between the glomerular filtration rate and the serum concentration of hepcidin (Peters, Laarakkers, Swinkels, \& Wetzels, 2010). Hepcidin-25 has both antimicrobial and ironregulatory activities, whereas hepcidin-22 and hepcidin-20 have only antimicrobial activity. Much is still unknown about the origin of the smaller isoforms. During prolonged storage of plasma at room temperature, it has been observed that a decrease in plasma hepcidin-25 was paralleled by an increase in the levels of the hepcidin-24, -22 and -20 isoforms. This means that all of the determinants for the conversion of hepcidin-25 to smaller inactive isoforms are present in the circulation, which may contribute to the functional suppression of hepcidin-25, which is significantly higher in patients with renal impairment (Laarakkers, et al., 2013). We found that hepcidin was expressed predominantly in the hepatocytes around the portal veins in mouse liver. Interestingly, ferroportin staining was also found to be much more prominent in the periportal areas.

\subsection{Hepcidin kinetics}

Binding to carrier proteins may prevent circulating hepcidin from being freely filtered (Peters, et al., 2010). Hepcidin preferentially binds to the blood glycoprotein, $\alpha_{2^{-}}$ macroglobulin ( $\left.\alpha_{2} M\right)$ and to methylamine-activated $\alpha_{2} M\left(\alpha_{2} M-M A\right) . \alpha_{2} M$, which is composed of subunits with tetrameric structures in vertebrates, protects the body against various infections, and hence, can be used as a biomarker for the diagnosis and prognosis of a 
number of diseases (Rehman, Ahsan, \& Khan, 2013). Hepcidin binds to the methylamineactivated form of $\alpha_{2} \mathrm{M}$ via four high-affinity binding sites. In addition to hepcidin binding, both $\alpha_{2}$ Ms bind many hormones and cytokines such as IL-6. Hepcidin complexed with native and activated $\alpha_{2} \mathrm{M}$ significantly decreased FPN expression. Hepcidin bound to activated $\alpha_{2} \mathrm{M}$ binds to the $\alpha_{2} \mathrm{M}$ receptor: low density lipoprotein receptor-related protein-1 (Lrp1) on target cells. Activated $\alpha_{2} \mathrm{M}$ is internalized by endocytosis via these receptors (M. L. Huang, et al., 2013).

Hepcidin clearance is assumed to occur via cellular co-degradation with FPN at its sites of action, and via excretion by the kidneys. Because of its low molecular weight and small radius, unbound hepcidin probably passes freely into the glomerular filtrate. Possible local tubular production of hepcidin as well as possible defective tubular reabsorption of hepcidin must also be taken into account in the interpretation of urine levels as a mirror of serum hepcidin concentrations (Kulaksiz, et al., 2005). Recently, hepcidin-25 has been shown to have a direct correlation with creatinine and an inverse correlation with estimated glomerular filtration rate, suggesting that hepcidin-25 levels increase as renal function deteriorates, possibly due to decreased renal clearance of hepcidin-25 (Troutt, Butterfield, \& Konrad, 2013).

\section{Sources of extrahepatic hepcidin}

Apart from hepatocytes, which are the main source of circulating hepcidin, other cell types such as macrophages, adipocytes, and heart and stomach cells express hepcidin mRNA, but at a lower level. While extrahepatic hepcidin expression is becoming established, the physiological role of hepcidin in extrahepatic tissues is only partially understood. Extrahepatic hepcidin production may play a role in the local regulation of iron fluxes

\subsection{Macrophages}

Macrophages facilitate the rapid throughput of iron and strongly express FPN. The transport of iron across vacuolar membranes into the cytoplasm of macrophages involves DMT1, which is specific for ferrous iron. The necessary iron reduction is catalysed by an erythroid endosomal ferric reductase, which is important for iron utilization in erythrocytes.

A sequence of events takes place in macrophage lysosomes when they phagocytose senescent erythrocytes. The hydrolytic environment of the phagolysosome digests the 
erythrocyte and its haemoglobin, releasing haem, which is then degraded by inducible haem oxygenase-1 (HO-1). Iron is released for cytoplasmic storage or export to blood plasma; these processes may be particularly influenced by hepcidin. HO-1 acts within the phagolysosomes, and the released iron is transported across the phagolysosomal membrane. Macrophages are important producers of hepcidin, and within macrophages, hepcidin localizes in mycobacteria-containing phagosomes where it exerts its antimycobacterial activity (Layoun \& Santos, 2012). In macrophages, the regulation of lipopolysaccharide (LPS)-inducible cytokines, which include several endogenous compounds such as TNF $\alpha$, interleukin (IL) families and receptors, especially Toll-like receptors (TLRs) and IL-1R takes place. LPS-induced hepcidin expression in vivo is dependent on TLR4, indicating that TLR signalling may be important for the activation of hepcidin production in macrophages (figure 1) (Constante, et al., 2006). In contrast to hepcidin expression in hepatocytes, that in macrophages is positively regulated by gram-positive and gram-negative bacteria wall constituents through TLR2 and TLR4 (Layoun \& Santos, 2012). Hepcidin expression by macrophages increases following bacterial infection, and hepcidin decreases iron release from macrophages in an autocrine and/or paracrine manner. Though circulating hepcidin seems to be a relatively ineffective antimicrobial peptide, it was recently proposed that hepcidin produced endogenously by macrophages and localized in the phagosome could play a role in host defences against tuberculosis by causing structural damage to the mycobacteria (Sow, et al., 2011).

In monocytes, autocrine production of hepcidin has been shown to down-regulate FPN expression, thereby contributing to iron sequestration within these cells (Theurl, et al., 2008). The hepcidin-mediated elevation of intracellular iron plays an important role in the cytokine response of macrophages and hence subsequent immune responses (Layoun \& Santos, 2012). It has recently been proposed that High Mobility Group Box-1 (HMGB1), which is released from irradiated tumour cells, acts as an endogenous TLR4 ligand (Apetoh, et al., 2007). HMGB1 is a nuclear protein that can be released into the extracellular milieu from immune and non-immune cells in response to various stimuli. Extracellular HMGB1 contributes to the pathogenesis of numerous chronic inflammatory and autoimmune diseases, including sepsis, rheumatoid arthritis, atherosclerosis, chronic kidney disease and cancer. It has been suggested that there is some interplay between HO-1 and HMGB1 (Gong, et al., 2008). 
In atherosclerotic plaque, iron preferentially accumulates in macrophages where it can exert pro-oxidant activities (Yuan \& Li, 2003). The physiology of hepcidin suggests an additional mechanism by which iron depletion could protect against the progression of atherosclerotic lesions. Without hepcidin, macrophages retain less iron. Hepcidin may promote plaque destabilization by preventing iron mobilization from macrophages within atherosclerotic lesions. This process can be altered and the absence of this mobilization may result in increased cellular iron loads, thus inducing lipid peroxidation, which is associated with progression to foam cells (Sullivan, 2007).

Interestingly, it was recently demonstrated that after exposure to iron, differentiated macrophages (M2) completely changed their phenotype and acquired a phenotype oriented to iron release. The iron handling ability of $M 2$ macrophages suggests they play a modulatory role in atherosclerosis. Hepcidin decreased iron loading in M2 macrophages, whereas FPT expression increased. Expression of the HO-1 gene and NRF2, which are markers of oxidative stress, also increased markedly in M2 macrophages. Finally, these M2 macrophages are highly specialized in iron recycling associated with increasing FPN expression and a decrease in hepcidin mRNA levels (Bories, et al., 2013).

\subsection{Adipocytes}

Recent data suggest that adipocytes are capable of producing hepcidin, and that this process is probably triggered by inflammatory stimuli. Hepcidin mRNA and hepcidin were present in adipose tissue, and mRNA levels in adipose tissue correlated with levels of IL-6 and Creactive protein (CRP) (Bekri, et al., 2006). Adipose tissue expressed hepcidin at both the mRNA and protein level and this expression was enhanced in obese patients (Vuppalanchi, et al., 2014). A lot of results point out that hepcidin may play an important role in the hypoferremia of inflammation in obese patients. There is a tight relationship between iron deficiency and obesity. Obesity seems to be associated with lower iron levels and higher iron stores, reflecting lower iron bioavailability, together with higher hepcidin production and with higher levels of obesity-related inflammation markers (Coimbra, Catarino, \& Santos-Silva, 2013). In this field, it has been reported that activin B was a new adipokine having a role in energy balance and insulin insensitivity associated with obesity (Dani, 2013). Interestingly, hepcidin synthesis was induced by inflammatory signals including activin B and 
SMAD responded to activin B (Akel, Bertolette, \& Ruscetti, 2013; Besson-Fournier, et al., 2012).

Interactions between cells in the blood vessel wall and regional lipids are vital for normal vascular function, and they are disturbed in cardiovascular diseases. Perivascular adipocytes are present at the adventitial border of blood vessels. The secretion of mediators that regulate inflammation is a characteristic feature of adipocytes. These mediators can be divided into two categories: adipokines and cytokines. Adipose tissue is known to secret IL-6, leptin and adiponectin (Rajsheker, et al., 2010). As we reported, hepcidin is rapidly induced by cytokines, including IL-6. In human volunteers, recombinant IL-6 infusion resulted in a 7.5fold increase in urine hepcidin levels, and serum iron decreased by $34 \%$ within $2 \mathrm{~h}$. IL-6 neutralizing antibodies were used to show that there was an IL-6-dependent inflammationmediated and regulatory-hepcidin pathway (Nemeth, Rivera, et al., 2004). It has been suggested that adipocytes are key regulators of metabolism in all tissues, given their integrated sensing of nutritional stores and iron availability. Evidence now exists that adipocyte iron levels regulate adiponectin transcription and serum protein levels (Gabrielsen, et al., 2012). High levels of leptin are found in obesity and also appear to contribute to the iron status observed in obesity. Leptin is capable of inducing hepatic hepcidin expression via the Janus kinase 2 (Jak2)/STAT3 signalling pathway, which is similar to IL-6-mediated hepcidin expression. STAT3 belongs to the signal transducer and activator of transcription (STAT) family of signal responsive transcription factors. In non-stimulated cells, STAT3 is kept in an inactive cytoplasmic form. The JAK2/STAT3 pathway is a stressresponse mechanism that transduces signals from the cell surface to the nucleus, thereby modulating gene expression (Chung, Matak, McKie, \& Sharp, 2007; Meli, et al., 2013). Certain studies have reported that circulating hepcidin and leptin concentrations in obese patients are higher than those in normal-weight subjects. These observations support the idea that the poor iron status frequently observed in obese patients may be associated with the hepcidin-mediated inhibition of dietary iron absorption (Amato, et al., 2010). As we previously reported in the underlying mechanism of iron-regulated hepcidin expression, several proteins that participate in this process have been identified. Among these, hemojuvelin (HJV) plays a particularly important role. A soluble form of hemojuvelin (s-HJV) exists in the blood. Recently, it has been reported that HJV was also expressed in adipocytes at mRNA and protein levels. Moreover, its mRNA expression was greatly increased in 
adipose tissue from obese individuals and correlated positively with hepcidin expression levels (Luciani, et al., 2011).

\subsection{Heart}

It has been reported that increased levels of iron and iron-mediated injury play an important role in the development of a number of heart disorders, including iron-overload cardiomyopathy, acute myocardial infarction and coronary heart diseases (Rochette, et al., 2011; Tuomainen, Punnonen, Nyyssonen, \& Salonen, 1998). Heart cells have the ability to accumulate transferrin-bound-iron via the Tf receptor and non-transferrin-bound-iron probably via the L-type $\mathrm{Ca}^{2+}$ channel. FPN-mediated iron export is dependent on the ferroxidase activity of the multicopper oxidases, ceruloplasmin and hephaestin (Qian, et al., 2007). It has also been demonstrated that hepcidin was expressed in the heart; this implies that this protein might play a role in iron homeostasis in the heart. In vitro, it has been demonstrated that hepcidin was able to bind with FPN, internalize and degrade FPN, and thus decrease iron export from heart cells (Ge, et al., 2009; Merle, Fein, Gehrke, Stremmel, \& Kulaksiz, 2007).

In our laboratory; we found that hepcidin was present in the myocardium. The protein was diffusely expressed in the myocardium (Figure 3). Recently, cardiac expression of hepcidin in different conditions: rat experimental autoimmune myocarditis (EAM), rat acute myocardial infarction (AMI) and human myocarditis have been investigated. Hepcidin mRNA was moderately expressed in the heart of normal rats, but the expression of hepcidin mRNA in the heart of EAM rats was markedly greater than that in controls. In humans, the level of hepcidin/cytochrome oxidase mRNA in hearts with pathologically diagnosed myocarditis was significantly higher than that in hearts without myocarditis. Finally, hepcidin expression is more strongly influenced by local environmental conditions than by systemic conditions; hepcidin mRNA levels correlated with those of IL-6 mRNA (Isoda, et al., 2010). In hypoxic rat hearts, expression levels of hepcidin were highest at the myocardial intercalated disc area (Merle, et al., 2007). Given this localization, it is logical to conclude that the presence of hepcidin in the intercalated disc area may be an important component in a local response to an inflammatory process.

Another condition that induces hepcidin expression is inflammation associated with cardiac diseases such as heart failure. Increases in proinflammatory cytokine levels and anaemia 
have been reported in patients with heart failure. It is possible that the increased level of inflammatory cytokines in the heart may induce hepcidin gene expression in cardiomyocytes (Nemeth, et al., 2003). A large number of transgenic over-expression studies that investigated a wide array of intracellular signalling pathways in the hypertrophic response have been published. Using transgenic models, it appears that hepcidin in the heart plays a role in the regulation of iron homeostasis in an autocrine and paracrine fashion (Zhang, et al., 2012).

\subsection{Stomach}

Given the established role of the stomach and gut in iron metabolism, it is tempting to speculate that the hepcidin system is implicated in the regulatory and antimicrobial functions of iron. A recent study showed that hepcidin was expressed in gastric parietal cells (Schwarz, et al., 2012). In mice and rats, quantitative RT-PCR analyses revealed abundant hepcidin expression in the fundus/corpus part of the glandular stomach, and less ample expression in the antrum. The influence of hepcidin on gastric acid secretion and the regulation of gastric acid production may also contribute to local iron homeostasis. Hepcidin is also present in the bile (Strnad, et al., 2011). Hepcidin was increased after treatment with proton pump inhibitors and reduced after the injection of histamine; these results suggest that hepcidin signalling serves as a mechanism to keep gastric acid secretion steady under normal and pathological conditions such as inflammation. Iron absorption is diminished during inflammation, and the mechanisms operating in the intestine to decrease iron absorption during inflammation have been poorly studied at the cellular level. Treatment with TNF alpha decreased intestinal iron absorption, but TNF appears to mediate hypoferremia independenly of hepcidin (Schubert, et al., 2012). One study investigated whether hepcidin was implicated in colon cancer-associated anaemia and whether it might play a role in colorectal carcinogenesis. Hepcidin is expressed by colorectal cancer tissue and thus may be a novel oncogenic signalling mechanism (Ward, et al., 2008).

\section{Importance of the hepcidin-ferroportin interaction (figure 4)}

The interaction of hepcidin with FPN provides a mechanism for coordinating the entry of iron into the plasma with iron utilization and storage. Recent advances in understanding the molecular mechanisms of hepcidin regulation in particular in relationship with FPN and its 
targets came from studying patients with a genetic iron overloaded disorder such as haemochromatosis. These patients present mutations in genes that encode different proteins and they have low hepcidin levels relative to iron stores (Gao, et al., 2009).

The main target of hepcidin is FPN, the transmembrane protein responsible for iron export from cells to plasma (Nemeth, Tuttle, et al., 2004). FPN protein is encoded by the SLC40A1 gene located on chromosome 2 (2q32). FPN gene mutations have been identified in different ethnic populations and some of the mutations are associated with autosomal dominant iron overload disorder. To date, forty-five mutations in the SLC40A1 gene have been described in people of different ethnicity, and this number is set to increase as more mutations are discovered. In the majority of cases, FPN polymorphism is a result of a missense mutation (Kasvosve, 2013). Mutations in the FPN gene lead to autosomal dominant iron overload diseases (Detivaud, et al., 2013). Hepcidin binds to a highly conserved domain on an extracellular loop of FPN. The extracellular loop of FPN that interacts with hepcidin was identified from the observation that the Cys326 mutation in this loop resulted in FPN being resistant to hepcidin binding. It has been proposed that the free thiol of the Cys326 residue forms a disulphide bond with one of the cysteine residues in hepcidin (Clark, et al., 2011). The concentration of FPN on the surface of cells depends on the rate of synthesis, the hepcidin/FPN interaction, the rate of internalization and the rate of cellular degradation. Once internalized, FPN is dephosphorylated and subsequently ubiquitinated. The inability to ubiquitinate FPN does not prevent hepcidin-induced internalization, but it inhibits the degradation of FPN. Ubiquitinated FPN is trafficked through the multivesicular body pathway en route to degradation in the endosome (De Domenico, et al., 2007).

It has been demonstrated that the kinase responsible for the phosphorylation of FPN is JAK2. Binding of JAK2 to FPN is highly cooperative and requires hepcidin to bind to both monomers of the FPN dimer and both monomers to be capable of activating JAK2 (De Domenico, Lo, Ward, \& Kaplan, 2009). Studies have suggested that a thiol-disulphide exchange may occur during hepcidin binding to FPN (Preza, et al., 2011). Once bound, JAK2 is autophosphorylated and then phosphorylates FPN, leading to FPN internalization (De Domenico, et al., 2009).

In summary, excess iron induces an increase in hepcidin concentration, resulting in the internalization and degradation of FPN protein. Intracellular iron is then sequestered by binding to ferritin within cells, limiting the increase in plasma iron concentration and Tf 
saturation. Coupling the internalization of FPN to hepcidin levels could generate a homeostatic loop that regulates iron plasma levels and the tissue distribution of iron.

\section{Hepcidin: master regulator of iron metabolism}

When iron stores are adequate or high, the liver produces hepcidin, which circulates to the small intestine. FPN molecules are expressed on the basolateral membranes of enterocytes, and they transport iron from enterocytes to plasma transferrin. Hepcidin causes FPN to be internalized, thus blocking the pathway for the transfer of iron from enterocytes or macrophages to plasma. Macrophages export $\mathrm{Fe}^{2+}$ from their plasma membrane via FPN, in a process coupled with the re-oxidation of $\mathrm{Fe}^{2+}$ to $\mathrm{Fe}^{3+}$ by ceruloplasmin and followed by the loading of $\mathrm{Fe}^{3+}$ onto Tf. Exported iron is scavenged by Tf, which maintains $\mathrm{Fe}^{3+}$ in a redoxinert state and delivers it into tissues. The copper-containing ferroxidase, hephaestin, assists by converting $\mathrm{Fe}^{2+}$ to $\mathrm{Fe}^{3+}$, which is then bound by Tf.

As we previously reported, iron enters the cell from the bloodstream in a complex with Tf, which binds to receptors TfR1 and TfR2 on the plasma membrane, followed by receptormediated endocytosis. As stated above, human TfR1 and TfR2 are very similar, being 45\% homologous and 60\% similar in their primary structure (Anderson \& Vulpe, 2009; Bayeva, Chang, Wu, \& Ardehali, 2013; Koskenkorva-Frank, Weiss, Koppenol, \& Burckhardt, 2013). Under physiological conditions, plasma Tf is hyposaturated (to $~ 30 \%$ ) and displays a very high iron-binding capacity.

Different studies have revealed that expression of the hepcidin-FPN axis was regulated by different factors (exogenous and endogenous). At the molecular level, the pathways involved in this regulation are not well known. The effect of vitamin D on the hepcidin-FPN axis suggests that low vitamin D status may be a contributing factor to the anaemia of chronic kidney disease (CKD), which is characterized by impaired vitamin D status, which itself is closely associated with adverse CKD health outcomes. Recently, a study showed for the first time that vitamin $D$ was a potent regulator of hepcidin in both monocytes and hepatocytes (Bacchetta, et al., 2014). In conditions of vitamin D deficiency, elevated synthesis of hepcidin by hepatocytes may increase intracellular and systemic concentrations of hepcidin and thus decrease membrane expression of FPN in these cells. Direct transcriptional suppression of hepcidin gene (HAMP) expression mediated by 1,25- 
dihydroxyvitamin $D$ binding to the vitamin $D$ receptor causes a decrease in hepcidin mRNA levels.

Studies have reported a decrease in hepcidin expression in response to hypoxia. However, the physiological relevance of hypoxia and its impact on hepcidin regulation are still uncertain and conflicting. In vivo, hypoxia could also suppress hepcidin indirectly through erythropoiesis and enhanced iron use. Hypoxia-inducible factor (HIF) may, however, contribute to hepcidin suppression indirectly via its effects on the breakdown of hemojuvelin (Silvestri, Pagani, \& Camaschella, 2008). Moreover, HIF1 $\alpha$ and $2 \alpha$ were shown to increase intestinal iron absorption, iron uptake into erythroid progenitors and haem synthesis, and to suppress hepcidin production thus ensuring an adequate supply of iron to support erythropoiesis (Evstatiev \& Gasche, 2012; Palaneeswari, Ganesh, Karthikeyan, Devi, \& Mythili, 2013). In the HIGHCARE study (HIGH altitude Cardiovascular Research carried out 3400-5400 $\mathrm{m}$ above sea level) the modifications induced by acute and chronic exposure to hypobaric hypoxia on serum iron indices, EPO, IL-6, and hepcidin levels were investigated. Hepcidin levels decreased within 40 hours after acute hypoxia exposure at $3400 \mathrm{~m}$ and reached the lowest level at $5400 \mathrm{~m}$. This fall was associated with a rapid decrease in serum levels of ferritin. The strong correlation between serum ferritin and hepcidin during the study indicates that iron itself or the kinetics of iron use in response to hypoxia may signal hepcidin down-regulation (Piperno, et al., 2011).

In the process of hepcidin regulation, the endoplasmic reticulum may play a role with regard to inflammation. The acute inflammatory response has been linked to endoplasmic reticulum (ER) stress, a state that is associated with disruption of ER homeostasis and the accumulation of unfolded or misfolded proteins in the ER. Overall, it appears that the regulation of hepcidin by ER stress links the cellular response involved in protein quality control to innate immunity and iron homeostasis. Apparently, hepcidin reacts not only to extracellular stimuli, such as iron fluctuations and cytokines, but also to stress signals arising within the cell (Oliveira, de Sousa, \& Pinto, 2011; Vecchi, et al., 2009).

Among the endogenous "mediators"; carbon monoxide (CO) and NO appear to play a role in this regulation. CO suppresses hepcidin expression elicited by IL- 6 and endoplasmic reticulum-stress agents by inhibiting signal transducer and activator of transcription (STAT-3) phosphorylation and cyclic AMP response element-binding protein-H (CREBH) maturation, respectively. The induction of endoplasmic reticulum stress in mice resulted in increased 
hepatic and serum hepcidin (Shin, et al., 2012). The anti-inflammatory action of CO is implicated in these different processes (Rochette, Cottin, Zeller, \& Vergely, 2013).

Concerning NO, it has been hypothesized that iron homeostasis and NO biology are interconnected (see previous paragraph: Role of Ferritin). As we previously mentioned, the regulation of ferritin synthesis by iron is mainly due to post-transcriptional regulation through the binding of IRP1 and IRP2 to IRE and the NO-induced expression of FPN (Nairz, et al., 2013; Straub, et al., 2012). Several reports indicate a potential synergistic effect between $\mathrm{NO}$ and $\mathrm{H}_{2} \mathrm{~S}$ in controlling various biological responses of vascular function. It is interesting to note that the cytoprotective functions of low concentrations of $\mathrm{H}_{2} \mathrm{~S}$ are comparable to those of NO. Importantly, NO and hydrogen can react rapidly with metalloproteins such as ironsulphur clusters (Kolluru, Shen, Bir, \& Kevil, 2013; Yin, Wang, \& Bernstein, 2013).

\section{Regulation of hepcidin expression (figure 5)}

The expression of hepcidin is dependent on opposing signalling pathways: the combined effects of the various pathways will determine hepcidin levels. The systemic factors that alter hepcidin expression, such as anaemia or inflammation, are well established. However, the mechanism by which hepcidin production is regulated at the molecular level is still unclear.

$H F E$, the gene mutated in the most common form of hereditary hemochromatosis, plays a role in monitoring body iron status and then directing the adaptive hepcidin response. The HFE protein interacts with TfR1 at a site that overlaps with the binding site for Tf. A close correlation between Tf levels and hepatic hepcidin mRNA expression has been demonstrated following haemolysis (Frazer, et al., 2004). Furthermore, when Tf binds to TfR2, the ERK1/ERK2 and p38 MAP kinase pathways are activated, thus inducing hepcidin expression (Calzolari, et al., 2006). As mentioned above, inflammation stimulates hepcidin expression, which in turn causes the hypoferremia associated with inflammatory episodes. Although several pro-inflammatory cytokines have been shown to increase hepcidin expression, IL- 6 has been the best studied. It stimulates hepcidin transcription through STAT3 signalling. Several microbial-derived Toll-like receptor (TLR) ligands can induce hepcidin expression, perhaps via the induction of IL-6 (Darshan \& Anderson, 2009).The most recently described factor in the regulatory pathway in hepcidin expression is the BMP (bone 
morphogenetic protein)/ SMAD (Contraction of Sma and Mad) pathway: BMP/SMAD. It has also been demonstrated that dorsomorphin, a selective inhibitor of BMP-responsive SMAD phosphorylation, blocked the IL-6 mediated induction of hepcidin ( $\mathrm{Yu}$, et al., 2008). It appears that the coordinated regulation of hepcidin expression by BMP and IL6 may involve crosstalk at the level of signal transduction. These effects are influenced by the cellular microenvironment. The human genome encodes 20 BMPs (Miyazono, Kamiya, \& Morikawa, 2010). BMP6 is the specific endogenous regulator of hepcidin (Camaschella, 2009). Mutations in the genes encoding the ligand BMP6, the BMP coreceptor HJV, and the intracellular signalling molecule SMAD4 are associated with suppressing hepcidin expression. These actions are associated with tissue iron overload.

It is now recognized that the BMP6-HJV-SMAD signalling pathway plays a major role in hepcidin regulation and iron homeostasis (Babitt \& Lin, 2010). Stimulation by BMP6 and/or iron induces an increase in BMP6-HJV-SMAD pathway activity, possibly through a mechanism involving HFE and TfR2, leading to binding of SMAD complexes to BMPresponsive elements (BMP-REs) on the hepcidin promoter and the up-regulation of hepcidin transcription. The BMPs act by binding to complexes of two type I and two type II receptors (BMPR-I and BMPR-II) and modulating the expression of target genes through different signal transduction pathways. Signalling through the SMAD proteins is now characterized. The constitutively active kinase domains of type II receptors phosphorylate type I receptors, and this in turn activates the SMAD signalling pathway through phosphorylation of receptor SMADs (SMAD1, SMAD5 and SMAD8). These associate with co-SMADs (SMAD4) to form a heteromeric complex that translocates to the nucleus and stimulates the expression of a wide range of target genes, including the gene encoding hepcidin (Anderson \& Darshan, 2008). BMPs can also signal through SMAD-independent pathways, notably via MAP kinases (Nohe, Keating, Knaus, \& Petersen, 2004).

There are important interactions between the different pathways, and the involvement of other members of the regulatory network, such as growth differentiation factor-15 (GDF15), has also been reported. GDF15 expression is associated with cellular stress or apoptosis in several tissues. The unprocessed translated form of GDF-15 (pre-pro-GDF-15) is 308 AA long and includes the signal sequence (29 AA), the propeptide (167 AA) and a mature protein (112 AA), which contains a cysteine that binds for the transforming growth factor- $\beta$ superfamily (Tanno, Noel, \& Miller, 2010). GDF-15 has been found to be expressed by 
mature erythroblasts, which occur in diseases due to increasingly ineffective erythropoiesis such as thalassemia. It has been demonstrated that GDF-15 protein suppresses hepcidin secretion (Tanno, et al., 2007; Tanno, et al., 2010).Erythroblast expression of a second molecule named twisted gastrulation: Twisted Gastrulation Gene 1) (TWSG1) was explored as a potential erythroid regulator of hepcidin. TWSG1 interferes with BMP-mediated hepcidin expression and may act with GDF15 to deregulate iron homeostasis in thalassemia. SMAD signalling pathways are implicated in the cellular actions of GDF-15 and TWSG1 (Tanno, et al., 2009).

Recently, several studies have demonstrated that oestrogens regulate hepcidin expression via G-coupled protein 30 (GPR30)-BMP6-dependent signalling, indicating that oestrogen decreases iron absorption in the intestine. GPR30 has been localized to both the cell plasma membrane and the endoplasmic reticulum and has been reported to mediate the action of oestrogen as a steroid receptor. New data suggest that oestrogen directly participates in the regulation of hepatic hepcidin expression (Ikeda, et al., 2012).

As we previously reported, hepcidin expression in macrophages is regulated mainly through TLR2 and TLR4 receptors. The autocrine regulation of iron accumulation in macrophages by hepcidin may affect the levels of pro-inflammatory cytokine production. TLR2- and TLR4mediated hepcidin upregulation was completely abrogated in myeloid differentiation factor 88 (MyD88)-/- macrophages, suggesting that MyD88 signalling is required for hepcidin induction through TLRs (Layoun \& Santos, 2012). TLR signalling requires interactions of the Toll/IL-1 receptor (TIR) domains of the receptor and adaptor proteins. The interaction surfaces in the TLR4 TIR domain for the TLR4-TLR4, TLR4-MyD88 adapter-like (MAL), and TLR4-TRIF-related adapter molecule (TRAM) interaction have been identified (Bovijn, et al., 2012).

All of the clinical observations point to iron-responsive regulatory pathways and suggest that oxidative stress could be involved in IL-6 signalling for hepcidin production. During inflammation, cells are exposed to persistently elevated concentrations of superoxide and $\mathrm{H}_{2} \mathrm{O}_{2}$. This condition requires the tight regulation of iron homeostasis to prevent tissue damage via Fenton reactions. In neutrophils and macrophages, the membrane-associated NADPH oxidase (NOX2) generates superoxide that is converted to $\mathrm{H}_{2} \mathrm{O}_{2}$ by SODs (Brechard \& Tschirhart, 2008). Recently, it has been shown that very low concentrations of $\mathrm{H}_{2} \mathrm{O}_{2}$ were sufficient for the potent up-regulation of hepcidin in hepatoma cells and primary 
hepatocytes, as $\mathrm{H}_{2} \mathrm{O}_{2}$ acts synergistically with other inducers of hepcidin, such as IL-6. The effect of $\mathrm{H}_{2} \mathrm{O}_{2}$ on hepcidin is mainly mediated via STAT3, which is the classical inflammatory pathway for the regulation of hepcidin (Millonig, et al., 2012).

\section{Pharmacology: targeting the hepcidin-ferroportin axis (table 1)}

The hepcidin-FPN axis is the principal regulator of extracellular iron homeostasis in health and disease. Its manipulation via agonistic and antagonistic pathways is an attractive and novel therapeutic strategy. Hepcidin agonists include compounds that mimic the activity of hepcidin and agents that increase the production of hepcidin by targeting hepcidinregulatory molecules. Advances are being made in this area through the development of small-molecule modulators of hepcidin regulation pathways, neutralizing antibodies to hepcidin, and supra-active mini-hepcidins. Antagonists may prevent hepcidin-mediated FPN internalization by at least three distinct mechanisms: (1) preventing the interaction between hepcidin and FPN, (2) inhibiting hepcidin-induced ubiquitination of FPN, and (3) inhibiting the endocytosis pathway for FPN internalization.

\subsection{Direct and indirect hepcidin agonists}

\subsubsection{Mini-hepcidin: hepcidin analogs ( 7-9 aminoacid peptides)}

The use of natural hepcidin as a potential replacement therapy in hepcidin-deficient conditions has major limitations. The half-life of natural hepcidin is very short due to its rapid renal excretion. Oral absorption of hepcidin would be low due to its large size $(\sim 2.7$ kDa). A series of 7- to 9-amino acid peptides, "minihepcidins," that mimic the activity of hepcidin has been developed. The rationale for their design was facilitated by the identification of the region on hepcidin and FPN molecules that is critical for their binding. Mutagenesis studies and biomolecular modelling indicated that the first 9 amino acids of the hepcidin $\mathrm{N}$-terminus were important for hepcidin activity. Synthetic $\mathrm{N}$-terminal peptides were further engineered to increase their bioavailability (Preza, et al., 2011). Unnatural amino acids were introduced to increase resistance to proteolysis, and fatty acids were conjugated to prolong the half-life in the circulation and potentially increase oral absorption. One minihepcidin (PR65) has been tested. From the $\mathrm{N}$ to the $\mathrm{C}$ terminus, the primary sequence of PR65 was (all L-amino acids): iminodiacetic acid, threonine, histidine, diphenylalanine, $\beta$-homo proline, arginine, cysteine, arginine, and $\beta$-homo phenylalanine. 
The C-terminal carboxyamide was derivatized with polyethylene glycol (PEG) linker and palmitic acid groups (Preza, et al., 2011; Ramos, et al., 2012). Minihepcidins could be useful for the prevention of iron overload, or may be used in combination with phlebotomy or chelation for the treatment of existing iron overload (Fung \& Nemeth, 2013). Recently, a number of cyclic hepcidin analogues have been designed and synthesized with the aim to produce a cyclized hepcidin that maintains activity relative to native hepcidin. Cyclization of hepcidin results in highly stable peptides with a hepcidin-like fold. However, they do not induce FPN internalization in vitro (Clark, et al., 2013).

\subsubsection{TMPRSS6 a membrane serine protease}

TMPRSS6 also called matriptase-2 and produced by the liver is a type II plasma membrane serine protease (TTSP). The 811-AA human protein is synthesized as an inactive zymogen and autoactivated by proteolytic cleavage. TMPRSS6 mRNA expression has been demonstrated to be induced by erythropoietin and hypoxia and by acute iron deprivation at the protein level. Hemojuvelin (HJV) was the first biologically relevant exogenous substrate for matriptase-2 to be identified (Lee, 2009). TMPRSS6 is mutated in iron-refractory irondeficiency anaemia. It inhibits hepcidin expression by depressing BMP/SMAD signalling. In both animals and humans, mutations in TMPRSS6 result in elevated hepcidin expression and defective iron absorption, which consequently lead to iron-deficiency anaemia (Delbini, et al., 2010). Studies that identified TMPRSS6 variants associated with haematological parameters, suggest that TMPRSS6 is crucial in the control of iron homeostasis and normal erythropoiesis (Cau, Melis, Congiu, \& Galanello, 2010). It has been demonstrated that the treatment of mouse models of $\mathrm{HH}\left(\mathrm{Hfe}^{-/-}\right)$and $\beta$-thalassemia intermedia with TMPRSS6 siRNA formulated in lipid nanoparticles increased hepcidin expression and lessened iron loading in both experimental models (Schmidt, et al., 2013).

\subsubsection{BMP6 analogues and small molecule activators of STAT/SMAD pathways}

BMP6-SMAD signalling is one of the main regulatory mechanisms in the control of hepcidin expression. HFE interacts with the BMP6-SMAD signalling pathway, downstream of BMP6, to regulate hepcidin expression (Corradini, et al., 2010). One technical challenge is to generate antibodies that can specifically recognize BMP6 without significant cross-reactivity to other BMPs. BMP6-like agonists may have a role to play as a new concept in therapeutic strategy. 
A small-scale chemical screening study in zebrafish embryos identified the isoflavone genistein as an enhancer of hepcidin transcription (Zhen, et al., 2013). Genistein is a soyderived biologically active isoflavone that exhibits diverse health-promoting effects. A growing body of evidence shows that genistein presents pleiotropic effects. It influences lipid homeostasis and insulin resistance, and counteracts inflammatory processes (Nagaraju, Zafar, \& El-Rayes, 2013). The treatment of HepG2 cells with genistein increased both hepcidin transcript levels and promoter activity. The effect of genistein on hepcidin expression did not depend on increased cellular iron uptake, but was impaired by mutation of either BMP response elements or the STAT3-binding site in the hepcidin promoter (Zhen, et al., 2013). Genistein and other candidate molecules may subsequently be developed into new therapies for iron overload syndromes.

\subsection{Direct and indirect hepcidin antagonists}

\subsubsection{Antibodies, short interference RNA and antisense oligonucleotides against hepcidin}

\subsubsection{Monoclonal antibodies}

Strategies have been developed that neutralize hepcidin activity by directly binding to the hepcidin peptide through monoclonal antibodies (mAbs), engineered protein and RNA-based binders. High-affinity antibodies specific for human hepcidin (hHepc) have been generated, and hHepc knock-in mice have been produced. Hepcidin mRNA suppression or antibodymediated neutralization was able to overcome inflammation-induced anaemia in a mouse model (Sasu, et al., 2010). RNA interference (RNAi) and gene-silencing antisense oligonucleotides that target transcription or translation of hepcidin are other approaches to develop therapeutic strategies for inflammation-induced anaemia. Antisense oligonucleotides that inhibit the translation of hepcidin or its regulators, such as HJV, are currently in the discovery stages of development.

Surface markers, such as CD2, CD3, CD4, CD25, and CD52, expressed on T-cells have been discovered and are now specific therapeutic targets. CD52 mAb targets the cell surface CD52 and is effective in depleting lymphocytes through cytolytic effects in vivo. The aim of a recent study was to investigate the therapeutic effect of anti-mouse CD52 mAb on Fedeficient anaemia in inflammatory bowel disease. The results indicated that anti-CD52 therapy may ameliorate Fe-deficient anaemia (Wang, et al., 2014). Human or humanized mAbs against hepcidin have been developed by scientists at Lilly (US Patent 7820163) and 
Amgen (US Patent Application 12/022515). To examine the contribution of hepcidin to inflammatory anaemia, and the effect of mAbs, a mouse model of inflammation-induced anaemia was required (Sasu, et al., 2010). A humanized monoclonal antibody against hepcidin is in a phase I human trial. This study will evaluate the safety of LY2787106 in patients with cancer and anaemia.

\subsubsection{Anti-BMP6 monoclonal antibody and Antisense oligonucleotides}

Anti-BMP6 monoclonal antibody therapy is another option to specifically block BMP6mediated hepcidin regulation. The administration of anti-BMP mAb in healthy mice decreased hepatic hepcidin expression and increased serum iron levels (Andriopoulos, et al., 2009). In the Hfe transgenic mouse model of excess hepcidin and iron-deficiency anaemia, treatment with anti-BMP6 improved the anaemia by lowering hepcidin levels (Corradini, et al., 2010).

Antisense oligonucleotides that inhibit the translation of hepcidin or its regulators such as HJV are in the discovery stages of development. Systemic delivery of antisense molecules results in preferential delivery to the liver, making them possible agents to target hepcidin (Graham, et al., 1998). RNA-based targeting of hepcidin regulators, such as HJV antisense oligonucleotides and TfR2 siRNA, is under development. Treatment with TfR2 siRNA potently decreased hepcidin mRNA in a rat model of inflammation-induced anaemia (Querbes, et al., 2012).

\subsubsection{Anticalins: specific anti-hepcidin and Spiegelmer-based hepcidin}

Anticalins are a novel class of compounds, with applications in hepcidin pharmacology. They are engineered derivatives of naturally occurring binding proteins called lipocalins. Lipocalins are mediators in a context of inflammation. They present high target specificity, good tissue penetration and low immunogenicity. They are involved in the transport of small hydrophobic molecules such as steroids and lipids into the cell. Due to their compact molecular architecture (they comprise a single polypeptide chain), they could be of interest as a therapy (Gebauer \& Skerra, 2012). Recently, anticalin PRS-080, which specifically binds human hepcidin with sub-nanomolar affinity, has been described. It is a selective specific inhibitor that blocks the interaction between hepcidin and the FPN receptor. Significant dose-dependent and hepcidin-specific iron mobilization was observed in Cynomolgus 
monkeys, following a single $3 \mathrm{mg} / \mathrm{kg}$ i.v. bolus of PRS-080. A program is currently under way to organise the first human clinical trial.

Different Spiegelmer-based hepcidin binders have now been identified. Spiegelmers are Lenantiomeric oligonucleotides that can be designed to inhibit pharmacologically relevant target molecules. They bind to the targets in a manner comparable to antibodies. Given their non-natural, mirror-image nature, Spiegelmers are nuclease-resistant and immunologically passive. Spiegelmers can fold into distinct three-dimensional structures that generate highaffinity ligands (Klussmann, Nolte, Bald, Erdmann, \& Furste, 1996). The best binding Spiegelmer, NOX-H94, has been modified to the L-oligonucleotide itself (NOX-H94002) and its PEGylated variant NOX-H94. NOX-H94 is a structured mirror-image L-oligoribonucleotide that binds human hepcidin with high affinity, thereby blocking its biological function (Schwoebel, et al., 2013).

\subsubsection{Inhibitors of hepcidin production}

Inhibition of hepcidin is a potential therapeutic approach to improve the utilization of iron from intracellular stores in patients suffering from anaemia of chronic inflammation.

\subsubsection{Targeting the BMP6-HJV-SMAD pathway:}

As the BMP pathway plays a key role in stimulating hepcidin transcription, sequestration of BMP ligands could decrease hepcidin expression. Heparin, a glycosaminoglycan widely used as an anticoagulant, is known to bind BMPs. The treatment of mice with pharmacological doses of heparin inhibited liver hepcidin mRNA expression and SMAD phosphorylation, reduced spleen iron concentrations, and increased serum iron (Poli, et al., 2011). Heparins are efficient hepcidin inhibitors both in vitro and in vivo, but their anticoagulant activity limits their therapeutic use. Non-anticoagulant heparins, produced by $\mathrm{N}$-acetylation and oxidation/reduction (glycol-split) that abrogates antithrombin binding affinity, have recently been studied. These non-anticoagulant compounds impair BMP/SMAD signalling with no evident adverse effect in vivo (Poli, et al., 2014). They may offer a strategy for the treatment of diseases with high hepcidin levels. Inhibition of BMP type I receptor signalling by smallmolecule inhibitors was also effective in moderating iron-restricted anaemia. Through a structure-activity relationship study of dorsomorphin derivatives, optimized compounds (LDN-193189 or DM-3189) with higher activity and specificity on BMP type I receptors have 
been also developed (Cuny, et al., 2008). LDN-193189 lowers hepcidin levels, mobilizes spleen iron stores, increases serum iron and iron incorporation into reticulocytes (Sun, et al., 2013).

Concerning these compounds derived from dorsomorphin, various important off-target effects persist. Programs that aim to identify selective modulators have been developed. The challenge lies in the synthesis of potent and biologically available selective inhibitors of BMP type I receptor kinases. In this domain, 4-quinolyinyl substituted dorsomorphin helped to highlight novel roles of this receptor system in pathophysiological processes (Hong \& Yu, 2009).

Evidence of interplay between cholesterol and iron metabolism, has been demonstrated in macrophages. Data suggest that reducing intracellular free iron levels within macrophages by increasing the expression of macrophage FPN may be a promising strategy to increase the expression of cholesterol efflux transporters (Saeed, et al., 2012). LDN-193189, a small molecule inhibitor of BMP signalling, has been studied. Serum iron levels were significantly higher following treatment with LDN-193189. Peritoneal macrophages isolated after treatment with LDN193189 showed reduced intracellular iron and hydrogen peroxide production. To evaluate the effect on atherosclerosis, ApoE-/- mice on a high-cholesterol diet were treated with LDN-193189. Significant reductions were found in intraplaque Oil Red O-positive lipid area, total plaque area, and plaque severity, along with elevated ATP binding cassette transporter $A 1$ ( $A B C A 1)$ immunoreactivity within plaque macrophage-rich regions. These findings suggest that LDN-193189 increases the expression of ABCA1 in macrophages within atherosclerotic plaques, thus limiting plaque progression.

Soluble HJV-Fc fusion protein (sHJV.Fc) is another agent that prevents the interaction between BMPs and their receptors. SHJV is known to bind BMP6, and this results in decreased SMAD signalling in the cell and decreased hepcidin expression. sHJV is a soluble fragment of the membrane-linked BMP co-receptor HJV, and the soluble and membrane form have opposing effects on hepcidin expression. In this context, the pharmacological inhibition of hepcidin expression via this pathway results in the mobilization of iron from the reticulo-endothelial system, stimulation of erythropoiesis and the correction of anaemia (Theurl, et al., 2011).

Alcohol consumption has long been associated with changes in iron homeostasis. Anaemia and iron deficiency can be due to gastrointestinal blood loss arising from the complications 
of alcohol abuse. Iron-mediated cell signalling has been reported to be involved in the pathogenesis of experimental alcoholic liver disease (Harrison-Findik, 2009). The mechanism was recently shown to involve inhibition of the BMP-SMAD pathway. The inhibition of BMP receptor activation and signalling by alcohol may involve various mechanisms such as hypoxia in the liver and inhibition of SMADs binding to hepcidin promoter (Gerjevic, Liu, Lu, \& Harrison-Findik, 2012).

\subsubsection{Anti-cytokine agents}

Another targeting pathway is via anti-cytokine agents, since hepcidin expression is strongly induced by IL-6/STAT3. The benefit of these agents used to treat inflammatory diseases may be provided by reducing hepcidin expression. Anti-TNF $\alpha$ antibody (golimumab) in patients with rheumatoid arthritis is associated with a continuous decrease in hepcidin levels (Doyle, et al., 2013).

Targeting the erythropoietic pathway may also be a pharmacological strategy. A single injection of erythropoietin (EPO) in human volunteers results in a rapid reduction of serum hepcidin (Ashby, et al., 2010). Erythropoiesis-stimulating agents such as prolyl hydroxylase inhibitors have been tested in clinical trials. The increased production of EPO was able to lower hepcidin. Unfortunately, however, these biological effects were associated with major detrimental disorders (Schwoebel, et al., 2013).

\subsubsection{STAT3 inhibitors}

The high level of hepcidin expression linked to the STAT3 pathway led to the testing of STAT3 inhibitors. Treatment with small molecule STAT3 inhibitors such as AG490 and the synthetic peptide inhibitor of STAT3 (PPYLKTK) abolished hepcidin expression in mice. AG490 inhibits the phosphorylation of STAT3 by JAK2, while the PpYLKTK disrupts phospho-STAT3 dimerization, which is required for binding target genes (Fatih, et al., 2010). In anaemia, AG490 could be a possible strategy to attenuate hepcidin-mediated biological actions in order to enhance iron uptake through enterocytes and iron release from macrophages. Another STAT3 inhibitor is curcumin. It has been proposed as a therapeutic adjuvant during inflammation, and its potential iron chelating activity has been reported (Aggarwal \& Shishodia, 2006). Another way to inhibit hepcidin production is associated with blocking antibodies to the IL-6 ligand. This strategy resulted in hepcidin lowering effects. Siltuximab, 
previously known as CNTO 328, is a chimeric, immunoglobulin (Ig) GK mAb that binds and neutralizes human IL- 6 with high affinity and specificity with potential therapeutic effects (van Rhee, et al., 2010).

\subsubsection{Pharmacological compounds with hepcidin antagonistic properties}

One group of compounds with hepcidin antagonistic properties are cardiac glycosides. Nanomolar concentrations of cardiac glycosides prevent the internalization of FPN. These concentrations are much lower than those known to cause adverse effects (Riganti, et al., 2011).

Small molecules identified as hepcidin antagonists such as fursultiamin, thioxolone, and pyrithione zinc are FDA-approved compounds that contain a sulphur moiety with potential thiol-directed chemical reactivity. These compounds prevent the interaction between hepcidin and FPN. Fursultiamin, a vitamin B1 derivative, is the thiamine derivative, thiamine tetrahydrofurfuryl disulphide (TTFD), which is absorbed from the intestinal tract and converted into thiamine pyrophosphate (TPP). It plays an important role as a cofactor for enzymes of the metabolic pathways involved in the production of adenosine triphosphate (ATP). Because fursultiamin prevents hepcidin-mediated endocytosis of FPN, it is hypothesized that fursultiamin may prevent FPN ubiquitination and thus interfere with the hepcidin/FDN interaction (Fung, et al., 2013).

Recent advances in our understanding of the molecular mechanisms of iron regulation reveal that the production of hepcidin may be regulated by the vitamin environment. As we reported previously, in conditions of vitamin D deficiency, elevated synthesis of hepcidin by hepatocytes may increase intracellular and systemic concentrations of hepcidin and decrease membrane expression of FPN in these cells. On the other hand, iron bioavailability seems to be regulated by antioxidant vitamins. Correlations between biomolecule oxidation products and iron status biomarkers have been observed in numerous studies (Cottin, et al., 1998; de Valk \& Marx, 1999). It has been proposed that hepcidin was able to protect tissue by inhibiting lipid peroxidation through indirect processes involving iron metabolism. The relationship between antioxidants and hepcidin mobilization appears complex given the versatility of iron as an oxidizing/reducing agent. The relationship between an antioxidant such as vitamin $\mathrm{C}$ and hepcidin expression has not yet been clearly explained. However, it is known that in patients with chronic renal failure, treatment with high doses of EPO or 
vitamin C can correct the functional iron deficiency (Pinto, et al., 2008). In a human liver carcinoma cell line (HepG2), it has been reported that vitamin $\mathrm{C}$ directly inhibits hepcidin expression (Chiu, Ko, \& Chang, 2012). Concerning the effect of vitamin A deficiency on iron status; vitamin A metabolites have been shown to affect the regulation of the synthesis and catabolism of proteins involved in iron metabolism. Vitamin A deficiency increased liver hepcidin mRNA levels (Arruda, Siqueira, \& de Valencia, 2009; Schroeder, Reddy, \& Schalinske, 2007).

A number of studies have highlighted the association between increased inflammatory indices and a reduced response to erythropoietin-stimulating agents (ESAs). It has been suggested that statins may have a positive impact on ESA responsiveness. A recent study showed that simvastatin significantly suppressed the mRNA expression of hepcidin in HepG2 cells (Chang, et al., 2013). Statins, which are inhibitors of 3-hydroxy-3-methyl glutaryl coenzyme A reductase, not only reduce lipid levels, but also have numerous pleiotropic effects. In fact, the precise molecular mechanisms responsible for changes in hepcidin mRNA expression are still unclear ( $\mathrm{Ha}, \mathrm{Ha}$, Theriault, \& Bhagavan, 2009). Statin therapy may improve responsiveness to erythropoietin-stimulating agents in patients with end-stage renal disease. Recent studies suggest that statins increase the erythropoiesis response by targeting hepcidin and iron regulation pathways, independently of erythropoietin (Chang, et al., 2013). One possible interpretation of these results is that the antioxidant properties of statins may be implicated in these effects (Sicard, et al., 2007; Sicard, et al., 2008).

\section{Hepcidin: an endogenous cytoprotective agent in cardiovascular pathophysiology and}

\section{possible therapeutic targets?}

The presence of hepcidin in body fluids raises questions about its function within these compartments. The role of hepcidin as an antimicrobial agent is well established (Verga Falzacappa \& Muckenthaler, 2005) and given that body fluids play an important role in the natural defences against inflammation, it is conceivable that hepcidin plays a role in cellular protection.

It is now well established that LPS mediates its effects through TLR4, for the induction of pro-inflammatory genes. LPS, potent inducers of pro-inflammatory cytokines, are responsible for endotoxic shock (Lecour, et al., 2002). Endotoxic shock is associated with a 
pro-inflammatory response and hypoferremia. Hepcidin has emerged as the possible pathogenic mediator of hypoferremia (Paya, Maupoil, Schott, Rochette, \& Stoclet, 1995). In cholestatic mice, pretreatment with hepcidin reversed the adverse effects of LPS administration and thus reduced early mortality. In this experimental model, pre-treatment with recombinant hepcidin significantly reduced LPS-induced pro-inflammatory cytokines and hepatocellular injury (Y. H. Huang, et al., 2012).

Myocardial protection aims to prevent reversible post-ischemic cardiac dysfunction and irreversible myocardial cell death (myocardial infarction) that occur as a consequence of myocardial ischemia and/or ischemic-reperfusion injury. Cardiopulmonary bypass (CPB) and the necessary period of ischemia-reperfusion are situations in cardiac surgery that promote oxidative stress. Reperfusion injury occurs, for example, after coronary artery bypass grafting when the ischemic myocardium is again provided with a supply of blood. Its most serious manifestations are arrhythmia and myocardial stunning, which are associated with free radical production (Clermont, et al., 2002; Goudeau, et al., 2007). The role of iron in reperfusion injury has been shown by indirect evidence: during reperfusion syndrome, the binding of iron to the chelator desferrioxamine protects the myocardium subjected to ischemia-reperfusion. The significant decrease in apoptosis in hearts treated with desferrioxamine could be considered evidence of a close link between iron chelation, oxidative stress and the promotion of apoptotic death in ischemia-reperfusion injury (Dobsak, et al., 2002; Galaris, Barbouti, \& Korantzopoulos, 2006). As we previously reported, hypoxia resulted in the strong up-regulation of hepcidin mRNA and protein expression in the heart. The regulated expression of hepcidin in the heart suggests that hepcidin may play an important role in the development of cardiac diseases (Merle, et al., 2007). CPB is a convenient and highly relevant model to study novel biomarkers of acute kidney injury (AKI). Urinary hepcidin has been suggested as a candidate biomarker of AKI (Ho, et al., 2009). In a clinical study, the relationship between changes in serum hepcidin, urinary hepcidin concentrations, and the urinary hepcidin/creatinine ratio were examined in a cohort of patients undergoing cardiothoracic surgery with CPB. Urinary hepcidin and the hepcidin/creatinine ratio were shown to be biomarkers of $A K I$ after CPB, with an inverse association between its increase at $24 \mathrm{~h}$ and the risk of AKI in the first five post-operative days (Prowle, et al., 2012). In a recent study, it was reported that serum hepcidin and urinary 
hepcidin increased immediately post-operatively and at $24 \mathrm{~h}$ (Haase-Fielitz, et al., 2013). In this study of 100 patients undergoing cardiac surgery, low preoperative urine and plasma hepcidin concentrations were predictors of in-hospital mortality. These results suggest that hepcidin plays an important role in modulating and determining the course and outcome of inflammation-mediated diseases.

Chronic heart failure (CHF) is a cardiovascular disease with a high rate of mortality. Anaemia is a common comorbility in these patients, and is associated with a worse prognosis. However, the physiopathology of anaemia in these patients is still not very well understood and is thought to be a complex and multifactorial process (Anand, 2008). Patients with CHF who became anaemic had higher levels of hepcidin (Martinez-Ruiz, et al., 2012).

Finally, as mentioned above, several reports suggest that hepcidin concentrations could be used to determine cardiovascular risk. It has been hypothesized that increased hepcidin concentrations may aggravate cardiovascular risk by modifying intracellular iron concentrations of macrophages and by increasing their atherogenic potential (Lapenna, et al., 2007).

\section{Conclusion}

Iron is the only micronutrient known to have a regulatory hormone, hepcidin, that responds to both nutrient status and infections. Hepcidin acts to block both iron absorption in the gut and iron release from macrophages through a common mechanism. The discovery of the hormonal iron-regulating role of hepcidin, followed by the elucidation of its mechanism of action has led to better understanding of the physiopathology of human iron disorders. Positive regulators of hepcidin, which lead to reduced ferroportin and decreased availability of iron, include increased circulating iron and inflammatory cytokines. Measuring levels of hepcidin could be useful in diagnosing several cardiovascular dysfunctions associated with haematological diseases. Iron-overload diseases are typically insidious and cause progressive and irreversible organ injury before clinical symptoms appear. In addition, better understanding of the relationship between the structure and function of hepcidin and the hepcidin-FPN complex may lead to the design of hepcidin antagonists and agonists for human therapy. The development of research in this domain offers new clinical potential in terms of diagnosis and therapy. 


\section{Acknowledgments}

The authors wish to thank Martine Goiset for secretarial assistance and Philip Bastable for English assistance. The authors acknowledge the essential technical contribution of Andre Bouchot (Histologie - Plateau Technique Imagerie Cellulaire) .

\section{Funding}

This work was supported by grants from the French Ministry of Research, from the Institut National de la Santé et de la Recherche Médicale (INSERM) and from the Regional Council of Burgundy.

\section{Conflict of interest}

The authors declare that there are no conflicts of interest 


\section{References}

Aggarwal, B. B., \& Shishodia, S. (2006). Molecular targets of dietary agents for prevention and therapy of cancer. Biochem Pharmacol, 71, 1397-1421.

Akel, S., Bertolette, D., \& Ruscetti, F. W. (2013). Crosstalk between the Smad and the MitogenActivated Protein Kinase Pathways is Essential for Erythroid Differentiation of Erythroleukemia Cells Induced by TGF-beta, Activin, Hydroxyurea and Butyrate. J Leuk (Los Angel), 1.

Alkhateeb, A. A., \& Connor, J. R. (2013). The significance of ferritin in cancer: anti-oxidation, inflammation and tumorigenesis. Biochim Biophys Acta, 1836, 245-254.

Amato, A., Santoro, N., Calabro, P., Grandone, A., Swinkels, D. W., Perrone, L., \& del Giudice, E. M. (2010). Effect of body mass index reduction on serum hepcidin levels and iron status in obese children. Int J Obes (Lond), 34, 1772-1774.

Anand, I. S. (2008). Anemia and chronic heart failure implications and treatment options. J Am Coll Cardiol, 52, 501-511.

Anderson, G. J., \& Darshan, D. (2008). Small-molecule dissection of BMP signaling. Nat Chem Biol, 4, 15-16.

Anderson, G. J., \& Vulpe, C. D. (2009). Mammalian iron transport. Cell Mol Life Sci, 66, 3241-3261.

Andriopoulos, B., Jr., Corradini, E., Xia, Y., Faasse, S. A., Chen, S., Grgurevic, L., Knutson, M. D., Pietrangelo, A., Vukicevic, S., Lin, H. Y., \& Babitt, J. L. (2009). BMP6 is a key endogenous regulator of hepcidin expression and iron metabolism. Nat Genet, 41, 482-487.

Apetoh, L., Ghiringhelli, F., Tesniere, A., Obeid, M., Ortiz, C., Criollo, A., Mignot, G., Maiuri, M. C., Ullrich, E., Saulnier, P., Yang, H., Amigorena, S., Ryffel, B., Barrat, F. J., Saftig, P., Levi, F., Lidereau, R., Nogues, C., Mira, J. P., Chompret, A., Joulin, V., Clavel-Chapelon, F., Bourhis, J., Andre, F., Delaloge, S., Tursz, T., Kroemer, G., \& Zitvogel, L. (2007). Toll-like receptor 4dependent contribution of the immune system to anticancer chemotherapy and radiotherapy. Nat Med, 13, 1050-1059.

Arruda, S. F., Siqueira, E. M., \& de Valencia, F. F. (2009). Vitamin A deficiency increases hepcidin expression and oxidative stress in rat. Nutrition, 25, 472-478.

Ashby, D. R., Gale, D. P., Busbridge, M., Murphy, K. G., Duncan, N. D., Cairns, T. D., Taube, D. H., Bloom, S. R., Tam, F. W., Chapman, R., Maxwell, P. H., \& Choi, P. (2010). Erythropoietin administration in humans causes a marked and prolonged reduction in circulating hepcidin. Haematologica, 95, 505-508.

Ashby, D. R., Gale, D. P., Busbridge, M., Murphy, K. G., Duncan, N. D., Cairns, T. D., Taube, D. H., Bloom, S. R., Tam, F. W., Chapman, R. S., Maxwell, P. H., \& Choi, P. (2009). Plasma hepcidin levels are elevated but responsive to erythropoietin therapy in renal disease. Kidney Int, 75, 976-981.

Babitt, J. L., \& Lin, H. Y. (2010). Molecular mechanisms of hepcidin regulation: implications for the anemia of CKD. Am J Kidney Dis, 55, 726-741.

Bacchetta, J., Zaritsky, J. J., Sea, J. L., Chun, R. F., Lisse, T. S., Zavala, K., Nayak, A., Wesseling-Perry, K., Westerman, M., Hollis, B. W., Salusky, I. B., \& Hewison, M. (2014). Suppression of ironregulatory hepcidin by vitamin D. J Am Soc Nephrol, 25, 564-572.

Bayeva, M., Chang, H. C., Wu, R., \& Ardehali, H. (2013). When less is more: novel mechanisms of iron conservation. Trends Endocrinol Metab, 24, 569-577.

Bekri, S., Gual, P., Anty, R., Luciani, N., Dahman, M., Ramesh, B., lannelli, A., Staccini-Myx, A., Casanova, D., Ben Amor, I., Saint-Paul, M. C., Huet, P. M., Sadoul, J. L., Gugenheim, J., Srai, S. K., Tran, A., \& Le Marchand-Brustel, Y. (2006). Increased adipose tissue expression of hepcidin in severe obesity is independent from diabetes and NASH. Gastroenterology, 131, 788-796.

Besson-Fournier, C., Latour, C., Kautz, L., Bertrand, J., Ganz, T., Roth, M. P., \& Coppin, H. (2012). Induction of activin $\mathrm{B}$ by inflammatory stimuli up-regulates expression of the iron-regulatory peptide hepcidin through Smad1/5/8 signaling. Blood, 120, 431-439. 
Bories, G., Colin, S., Vanhoutte, J., Derudas, B., Copin, C., Fanchon, M., Daoudi, M., Belloy, L., Haulon, S., Zawadzki, C., Jude, B., Staels, B., \& Chinetti-Gbaguidi, G. (2013). Liver X receptor activation stimulates iron export in human alternative macrophages. Circ Res, 113, 1196-1205.

Bovijn, C., Ulrichts, P., De Smet, A. S., Catteeuw, D., Beyaert, R., Tavernier, J., \& Peelman, F. (2012). Identification of interaction sites for dimerization and adapter recruitment in Toll/interleukin-1 receptor (TIR) domain of Toll-like receptor 4. J Biol Chem, 287, 4088-4098.

Brechard, S., \& Tschirhart, E. J. (2008). Regulation of superoxide production in neutrophils: role of calcium influx. J Leukoc Biol, 84, 1223-1237.

Cabantchik, Z. I. (2014). Labile iron in cells and body fluids: physiology, pathology, and pharmacology. Front Pharmacol, 5, 45.

Cairo, G., \& Recalcati, S. (2007). Iron-regulatory proteins: molecular biology and pathophysiological implications. Expert Rev Mol Med, 9, 1-13.

Calzolari, A., Raggi, C., Deaglio, S., Sposi, N. M., Stafsnes, M., Fecchi, K., Parolini, I., Malavasi, F., Peschle, C., Sargiacomo, M., \& Testa, U. (2006). TfR2 localizes in lipid raft domains and is released in exosomes to activate signal transduction along the MAPK pathway. J Cell Sci, 119, 4486-4498.

Camaschella, C. (2009). BMP6 orchestrates iron metabolism. Nat Genet, 41, 386-388.

Cau, M., Melis, M. A., Congiu, R., \& Galanello, R. (2010). Iron-deficiency anemia secondary to mutations in genes controlling hepcidin. Expert Rev Hematol, 3, 205-216.

Chang, C. C., Chiu, P. F., Chen, H. L., Chang, T. L., Chang, Y. J., \& Huang, C. H. (2013). Simvastatin downregulates the expression of hepcidin and erythropoietin in HepG2 cells. Hemodial Int, $17,116-121$.

Chiu, P. F., Ko, S. Y., \& Chang, C. C. (2012). Vitamin C affects the expression of hepcidin and erythropoietin receptor in HepG2 cells. J Ren Nutr, 22, 373-376.

Chung, B., Matak, P., McKie, A. T., \& Sharp, P. (2007). Leptin increases the expression of the iron regulatory hormone hepcidin in HuH7 human hepatoma cells. J Nutr, 137, 2366-2370.

Clark, R. J., Preza, G. C., Tan, C. C., van Dijk, J. W., Fung, E., Nemeth, E., Ganz, T., \& Craik, D. J. (2013). Design, synthesis, and characterization of cyclic analogues of the iron regulatory peptide hormone hepcidin. Biopolymers, 100, 519-526.

Clark, R. J., Tan, C. C., Preza, G. C., Nemeth, E., Ganz, T., \& Craik, D. J. (2011). Understanding the structure/activity relationships of the iron regulatory peptide hepcidin. Chem Biol, 18, 336343.

Clermont, G., Vergely, C., Jazayeri, S., Lahet, J. J., Goudeau, J. J., Lecour, S., David, M., Rochette, L., \& Girard, C. (2002). Systemic free radical activation is a major event involved in myocardial oxidative stress related to cardiopulmonary bypass. Anesthesiology, 96, 80-87.

Coimbra, S., Catarino, C., \& Santos-Silva, A. (2013). The role of adipocytes in the modulation of iron metabolism in obesity. Obes Rev, 14, 771-779.

Constante, M., Jiang, W., Wang, D., Raymond, V. A., Bilodeau, M., \& Santos, M. M. (2006). Distinct requirements for $\mathrm{Hfe}$ in basal and induced hepcidin levels in iron overload and inflammation. Am J Physiol Gastrointest Liver Physiol, 291, G229-237.

Corradini, E., Schmidt, P. J., Meynard, D., Garuti, C., Montosi, G., Chen, S., Vukicevic, S., Pietrangelo, A., Lin, H. Y., \& Babitt, J. L. (2010). BMP6 treatment compensates for the molecular defect and ameliorates hemochromatosis in Hfe knockout mice. Gastroenterology, 139, 1721-1729.

Corwin, H. L., \& Krantz, S. B. (2000). Anemia of the critically ill: "acute" anemia of chronic disease. Crit Care Med, 28, 3098-3099.

Cottin, Y., Doise, J. M., Maupoil, V., Tanniere-Zeller, M., Dalloz, F., Maynadie, M., Walker, M. K., Louis, P., Carli, P. M., Wolf, J. E., \& Rochette, L. (1998). Plasma iron status and lipid peroxidation following thrombolytic therapy for acute myocardial infarction. Fundam Clin Pharmacol, 12, 236-241.

Cuny, G. D., Yu, P. B., Laha, J. K., Xing, X., Liu, J. F., Lai, C. S., Deng, D. Y., Sachidanandan, C., Bloch, K. D., \& Peterson, R. T. (2008). Structure-activity relationship study of bone morphogenetic protein (BMP) signaling inhibitors. Bioorg Med Chem Lett, 18, 4388-4392. 
Dani, C. (2013). Activins in adipogenesis and obesity. Int J Obes (Lond), 37, 163-166.

Daniels, T. R., Bernabeu, E., Rodriguez, J. A., Patel, S., Kozman, M., Chiappetta, D. A., Holler, E., Ljubimova, J. Y., Helguera, G., \& Penichet, M. L. (2012). The transferrin receptor and the targeted delivery of therapeutic agents against cancer. Biochim Biophys Acta, 1820, 291-317.

Darshan, D., \& Anderson, G. J. (2009). Interacting signals in the control of hepcidin expression. Biometals, 22, 77-87.

De Domenico, I., Lo, E., Ward, D. M., \& Kaplan, J. (2009). Hepcidin-induced internalization of ferroportin requires binding and cooperative interaction with Jak2. Proc Natl Acad Sci U S A, 106, 3800-3805.

De Domenico, I., Ward, D. M., Langelier, C., Vaughn, M. B., Nemeth, E., Sundquist, W. I., Ganz, T., Musci, G., \& Kaplan, J. (2007). The molecular mechanism of hepcidin-mediated ferroportin down-regulation. Mol Biol Cell, 18, 2569-2578.

de Valk, B., \& Marx, J. J. (1999). Iron, atherosclerosis, and ischemic heart disease. Arch Intern Med, $159,1542-1548$.

Delbini, P., Vaja, V., Graziadei, G., Duca, L., Nava, I., Refaldi, C., \& Cappellini, M. D. (2010). Genetic variability of TMPRSS6 and its association with iron deficiency anaemia. $\mathrm{Br} J$ Haematol, 151, 281-284.

Delima, R. D., Chua, A. C., Tirnitz-Parker, J. E., Gan, E. K., Croft, K. D., Graham, R. M., Olynyk, J. K., \& Trinder, D. (2012). Disruption of hemochromatosis protein and transferrin receptor 2 causes iron-induced liver injury in mice. Hepatology, 56, 585-593.

Detivaud, L., Island, M. L., Jouanolle, A. M., Ropert, M., Bardou-Jacquet, E., Le Lan, C., Mosser, A., Leroyer, P., Deugnier, Y., David, V., Brissot, P., \& Loreal, O. (2013). Ferroportin diseases: functional studies, a link between genetic and clinical phenotype. Hum Mutat, 34, 15291536.

Dobsak, P., Siegelova, J., Wolf, J. E., Rochette, L., Eicher, J. C., Vasku, J., Kuchtickova, S., \& Horky, M. (2002). Prevention of apoptosis by deferoxamine during 4 hours of cold cardioplegia and reperfusion: in vitro study of isolated working rat heart model. Pathophysiology, 9, 27.

Doyle, M. K., Rahman, M. U., Frederick, B., Birbara, C. A., de Vries, D., Toedter, G., Wu, X., Chen, D., Ranganath, V. K., Westerman, M. E., \& Furst, D. E. (2013). Effects of subcutaneous and intravenous golimumab on inflammatory biomarkers in patients with rheumatoid arthritis: results of a phase 1, randomized, open-label trial. Rheumatology (Oxford), 52, 1214-1219.

Ebner, N., \& von Haehling, S. (2013). Iron deficiency in heart failure: a practical guide. Nutrients, 5, 3730-3739.

Evstatiev, R., \& Gasche, C. (2012). Iron sensing and signalling. Gut, 61, 933-952.

Fatih, N., Camberlein, E., Island, M. L., Corlu, A., Abgueguen, E., Detivaud, L., Leroyer, P., Brissot, P., \& Loreal, O. (2010). Natural and synthetic STAT3 inhibitors reduce hepcidin expression in differentiated mouse hepatocytes expressing the active phosphorylated STAT3 form. $J \mathrm{Mol}$ Med (Berl), 88, 477-486.

Frazer, D. M., Inglis, H. R., Wilkins, S. J., Millard, K. N., Steele, T. M., McLaren, G. D., McKie, A. T., Vulpe, C. D., \& Anderson, G. J. (2004). Delayed hepcidin response explains the lag period in iron absorption following a stimulus to increase erythropoiesis. Gut, 53, 1509-1515.

Fung, E., \& Nemeth, E. (2013). Manipulation of the hepcidin pathway for therapeutic purposes. Haematologica, 98, 1667-1676.

Fung, E., Sugianto, P., Hsu, J., Damoiseaux, R., Ganz, T., \& Nemeth, E. (2013). High-throughput screening of small molecules identifies hepcidin antagonists. Mol Pharmacol, 83, 681-690.

Gabrielsen, J. S., Gao, Y., Simcox, J. A., Huang, J., Thorup, D., Jones, D., Cooksey, R. C., Gabrielsen, D., Adams, T. D., Hunt, S. C., Hopkins, P. N., Cefalu, W. T., \& McClain, D. A. (2012). Adipocyte iron regulates adiponectin and insulin sensitivity. J Clin Invest, 122, 3529-3540.

Galaris, D., Barbouti, A., \& Korantzopoulos, P. (2006). Oxidative stress in hepatic ischemiareperfusion injury: the role of antioxidants and iron chelating compounds. Curr Pharm Des, $12,2875-2890$. 
Galesloot, T. E., Holewijn, S., Kiemeney, L. A., de Graaf, J., Vermeulen, S. H., \& Swinkels, D. W. (2014). Serum hepcidin is associated with presence of plaque in postmenopausal women of a general population. Arterioscler Thromb Vasc Biol, 34, 446-456.

Galesloot, T. E., Vermeulen, S. H., Geurts-Moespot, A. J., Klaver, S. M., Kroot, J. J., van Tienoven, D., Wetzels, J. F., Kiemeney, L. A., Sweep, F. C., den Heijer, M., \& Swinkels, D. W. (2011). Serum hepcidin: reference ranges and biochemical correlates in the general population. Blood, 117, e218-225.

Gammella, E., Buratti, P., Cairo, G., \& Recalcati, S. (2014). Macrophages: central regulators of iron balance. Metallomics, 6, 1336-1345.

Ganz, T. (2005). Hepcidin--a regulator of intestinal iron absorption and iron recycling by macrophages. Best Pract Res Clin Haematol, 18, 171-182.

Ganz, T. (2013). Systemic iron homeostasis. Physiol Rev, 93, 1721-1741.

Ganz, T., \& Nemeth, E. (2012). Hepcidin and iron homeostasis. Biochim Biophys Acta, 1823, 14341443.

Gao, J., Chen, J., Kramer, M., Tsukamoto, H., Zhang, A. S., \& Enns, C. A. (2009). Interaction of the hereditary hemochromatosis protein HFE with transferrin receptor 2 is required for transferrin-induced hepcidin expression. Cell Metab, 9, 217-227.

Ge, X. H., Wang, Q., Qian, Z. M., Zhu, L., Du, F., Yung, W. H., Yang, L., \& Ke, Y. (2009). The iron regulatory hormone hepcidin reduces ferroportin 1 content and iron release in H9C2 cardiomyocytes. J Nutr Biochem, 20, 860-865.

Gebauer, M., \& Skerra, A. (2012). Anticalins small engineered binding proteins based on the lipocalin scaffold. Methods Enzymol, 503, 157-188.

Gerjevic, L. N., Liu, N., Lu, S., \& Harrison-Findik, D. D. (2012). Alcohol Activates TGF-Beta but Inhibits BMP Receptor-Mediated Smad Signaling and Smad4 Binding to Hepcidin Promoter in the Liver. Int J Hepatol, 2012, 459278.

Gkouvatsos, K., Papanikolaou, G., \& Pantopoulos, K. (2012). Regulation of iron transport and the role of transferrin. Biochim Biophys Acta, 1820, 188-202.

Gong, Q., Yin, H., Fang, M., Xiang, Y., Yuan, C. L., Zheng, G. Y., Yang, H., Xiong, P., Chen, G., Gong, F. L., \& Zheng, F. (2008). Heme oxygenase-1 upregulation significantly inhibits TNF-alpha and Hmgb1 releasing and attenuates lipopolysaccharide-induced acute lung injury in mice. Int Immunopharmacol, 8, 792-798.

Goudeau, J. J., Clermont, G., Guillery, O., Lemaire-Ewing, S., Musat, A., Vernet, M., Vergely, C., Guiguet, M., Rochette, L., \& Girard, C. (2007). In high-risk patients, combination of antiinflammatory procedures during cardiopulmonary bypass can reduce incidences of inflammation and oxidative stress. J Cardiovasc Pharmacol, 49, 39-45.

Graham, M. J., Crooke, S. T., Monteith, D. K., Cooper, S. R., Lemonidis, K. M., Stecker, K. K., Martin, M. J., \& Crooke, R. M. (1998). In vivo distribution and metabolism of a phosphorothioate oligonucleotide within rat liver after intravenous administration. J Pharmacol Exp Ther, 286, 447-458.

Gudjoncik, A., Guenancia, C., Zeller, M., Cottin, Y., Vergely, C., \& Rochette, L. (2014). Iron, oxidative stress, and redox signaling in the cardiovascular system. Mol Nutr Food Res, 58, 1721-1738.

Ha, C. E., Ha, J. S., Theriault, A. G., \& Bhagavan, N. V. (2009). Effects of statins on the secretion of human serum albumin in cultured HepG2 cells. J Biomed Sci, 16, 32.

Haase-Fielitz, A., Plass, M., Kuppe, H., Hetzer, R., Ostland, V., Westphal, S., Hoffmann, J., Prowle, J., Mertens, P. R., Westerman, M., Bellomo, R., \& Haase, M. (2013). Low preoperative hepcidin concentration as a risk factor for mortality after cardiac surgery: a pilot study. J Thorac Cardiovasc Surg, 145, 1380-1386.

Harrison-Findik, D. D. (2009). Is the iron regulatory hormone hepcidin a risk factor for alcoholic liver disease? World J Gastroenterol, 15, 1186-1193.

Hentze, M. W., Muckenthaler, M. U., \& Andrews, N. C. (2004). Balancing acts: molecular control of mammalian iron metabolism. Cell, 117, 285-297. 
Ho, J., Lucy, M., Krokhin, O., Hayglass, K., Pascoe, E., Darroch, G., Rush, D., Nickerson, P., Rigatto, C., \& Reslerova, M. (2009). Mass spectrometry-based proteomic analysis of urine in acute kidney injury following cardiopulmonary bypass: a nested case-control study. Am J Kidney Dis, 53, 584-595.

Hong, C. C., \& Yu, P. B. (2009). Applications of small molecule BMP inhibitors in physiology and disease. Cytokine Growth Factor Rev, 20, 409-418.

Huang, M. L., Austin, C. J., Sari, M. A., Rahmanto, Y. S., Ponka, P., Vyoral, D., \& Richardson, D. R. (2013). Hepcidin bound to alpha2-macroglobulin reduces ferroportin-1 expression and enhances its activity at reducing serum iron levels. J Biol Chem, 288, 25450-25465.

Huang, Y. H., Yang, Y. L., Tiao, M. M., Kuo, H. C., Huang, L. T., \& Chuang, J. H. (2012). Hepcidin protects against lipopolysaccharide-induced liver injury in a mouse model of obstructive jaundice. Peptides, 35, 212-217.

Ikeda, Y., Tajima, S., Izawa-Ishizawa, Y., Kihira, Y., Ishizawa, K., Tomita, S., Tsuchiya, K., \& Tamaki, T. (2012). Estrogen regulates hepcidin expression via GPR30-BMP6-dependent signaling in hepatocytes. PLoS One, 7, e40465.

Isoda, M., Hanawa, H., Watanabe, R., Yoshida, T., Toba, K., Yoshida, K., Kojima, M., Otaki, K., Hao, K., Ding, L., Tanaka, K., Takayama, T., Kato, K., Okura, Y., Kodama, M., Ota, Y., Hayashi, J., \& Aizawa, Y. (2010). Expression of the peptide hormone hepcidin increases in cardiomyocytes under myocarditis and myocardial infarction. J Nutr Biochem, 21, 749-756.

Kansagara, D., Dyer, E., Englander, H., Fu, R., Freeman, M., \& Kagen, D. (2013). Treatment of anemia in patients with heart disease: a systematic review. Ann Intern Med, 159, 746-757.

Kasvosve, I. (2013). Effect of ferroportin polymorphism on iron homeostasis and infection. Clin Chim Acta, 416, 20-25.

Klopfleisch, R., \& Olias, P. (2012). The pathology of comparative animal models of human haemochromatosis. J Comp Pathol, 147, 460-478.

Klussmann, S., Nolte, A., Bald, R., Erdmann, V. A., \& Furste, J. P. (1996). Mirror-image RNA that binds D-adenosine. Nat Biotechnol, 14, 1112-1115.

Kolluru, G. K., Shen, X., Bir, S. C., \& Kevil, C. G. (2013). Hydrogen sulfide chemical biology: pathophysiological roles and detection. Nitric Oxide, 35, 5-20.

Kom, G. D., Schwedhelm, E., Nielsen, P., \& Boger, R. H. (2006). Increased urinary excretion of 8-isoprostaglandin F2alpha in patients with HFE-related hemochromatosis: a case-control study. Free Radic Biol Med, 40, 1194-1200.

Koskenkorva-Frank, T. S., Weiss, G., Koppenol, W. H., \& Burckhardt, S. (2013). The complex interplay of iron metabolism, reactive oxygen species, and reactive nitrogen species: Insights into the potential of various iron therapies to induce oxidative and nitrosative stress. Free Radic Biol Med, 65, 1174-1194.

Krause, A., Neitz, S., Magert, H. J., Schulz, A., Forssmann, W. G., Schulz-Knappe, P., \& Adermann, K. (2000). LEAP-1, a novel highly disulfide-bonded human peptide, exhibits antimicrobial activity. Febs Letters, 480, 147-150.

Kulaksiz, H., Theilig, F., Bachmann, S., Gehrke, S. G., Rost, D., Janetzko, A., Cetin, Y., \& Stremmel, W. (2005). The iron-regulatory peptide hormone hepcidin: expression and cellular localization in the mammalian kidney. J Endocrinol, 184, 361-370.

Laarakkers, C. M., Wiegerinck, E. T., Klaver, S., Kolodziejczyk, M., Gille, H., Hohlbaum, A. M., Tjalsma, H., \& Swinkels, D. W. (2013). Improved mass spectrometry assay for plasma hepcidin: detection and characterization of a novel hepcidin isoform. PLoS One, 8, e75518.

Lapenna, D., Pierdomenico, S. D., Ciofani, G., Ucchino, S., Neri, M., Giamberardino, M. A., \& Cuccurullo, F. (2007). Association of body iron stores with low molecular weight iron and oxidant damage of human atherosclerotic plaques. Free Radic Biol Med, 42, 492-498.

Lawen, A., \& Lane, D. J. (2013). Mammalian iron homeostasis in health and disease: uptake, storage, transport, and molecular mechanisms of action. Antioxid Redox Signal, 18, 2473-2507.

Layoun, A., \& Santos, M. M. (2012). Bacterial cell wall constituents induce hepcidin expression in macrophages through MyD88 signaling. Inflammation, 35, 1500-1506. 
Lecour, S., Chevet, D., Maupoil, V., Moisant, M., Bernard, C., Zahnd, J. P., Touchard, G., Briot, F., \& Rochette, L. (2002). Intrarenal detection of nitric oxide using electron spin resonance spectroscopy in hypertensive lipopolysaccharide-treated rats. J Cardiovasc Pharmacol, 40, 917.

Lee, P. (2009). Role of matriptase-2 (TMPRSS6) in iron metabolism. Acta Haematol, 122, 87-96.

Li, X., Li, H., Lu, N., Feng, Y., Huang, Y., \& Gao, Z. (2012). Iron increases liver injury through oxidative/nitrative stress in diabetic rats: Involvement of nitrotyrosination of glucokinase. Biochimie, 94, 2620-2627.

Lian, J., Xu, L., Huang, Y., Le, Y., Jiang, D., Yang, X., Xu, W., Huang, X., Dong, C., Ye, M., Zhou, J., \& Duan, S. (2013). Meta-analyses of HFE variants in coronary heart disease. Gene, 527, 167173.

Luciani, N., Brasse-Lagnel, C., Poli, M., Anty, R., Lesueur, C., Cormont, M., Laquerriere, A., Folope, V., LeMarchand-Brustel, Y., Gugenheim, J., Gual, P., Tran, A., \& Bekri, S. (2011). Hemojuvelin: a new link between obesity and iron homeostasis. Obesity (Silver Spring), 19, 1545-1551.

Ma, Y., Zhou, T., Kong, X., \& Hider, R. C. (2012). Chelating agents for the treatment of systemic iron overload. Curr Med Chem, 19, 2816-2827.

MacKenzie, E. L., Iwasaki, K., \& Tsuji, Y. (2008). Intracellular iron transport and storage: from molecular mechanisms to health implications. Antioxid Redox Signal, 10, 997-1030.

Martinez-Ruiz, A., Tornel-Osorio, P. L., Sanchez-Mas, J., Perez-Fornieles, J., Vilchez, J. A., MartinezHernandez, P., \& Pascual-Figal, D. A. (2012). Soluble TNFalpha receptor type I and hepcidin as determinants of development of anemia in the long-term follow-up of heart failure patients. Clin Biochem, 45, 1455-1458.

Meli, R., Mattace Raso, G., Irace, C., Simeoli, R., Di Pascale, A., Paciello, O., Pagano, T. B., Calignano, A., Colonna, A., \& Santamaria, R. (2013). High Fat Diet Induces Liver Steatosis and Early Dysregulation of Iron Metabolism in Rats. PLoS One, 8, e66570.

Merle, U., Fein, E., Gehrke, S. G., Stremmel, W., \& Kulaksiz, H. (2007). The iron regulatory peptide hepcidin is expressed in the heart and regulated by hypoxia and inflammation. Endocrinology, 148, 2663-2668.

Millonig, G., Ganzleben, I., Peccerella, T., Casanovas, G., Brodziak-Jarosz, L., Breitkopf-Heinlein, K., Dick, T. P., Seitz, H. K., Muckenthaler, M. U., \& Mueller, S. (2012). Sustained submicromolar H2O2 levels induce hepcidin via signal transducer and activator of transcription 3 (STAT3). J Biol Chem, 287, 37472-37482.

Miyazono, K., Kamiya, Y., \& Morikawa, M. (2010). Bone morphogenetic protein receptors and signal transduction. J Biochem, 147, 35-51.

Moyer, T. P., Highsmith, W. E., Smyrk, T. C., \& Gross, J. B., Jr. (2011). Hereditary hemochromatosis: laboratory evaluation. Clin Chim Acta, 412, 1485-1492.

Munoz-Bravo, C., Gutierrez-Bedmar, M., Gomez-Aracena, J., Garcia-Rodriguez, A., \& Navajas, J. F. (2013). Iron: protector or risk factor for cardiovascular disease? Still controversial. Nutrients, 5, 2384-2404.

Munoz, M., Garcia-Erce, J. A., \& Remacha, A. F. (2011). Disorders of iron metabolism. Part II: iron deficiency and iron overload. J Clin Pathol, 64, 287-296.

Murphy, C. J., \& Oudit, G. Y. (2010). Iron-overload cardiomyopathy: pathophysiology, diagnosis, and treatment. J Card Fail, 16, 888-900.

Nagaraju, G. P., Zafar, S. F., \& El-Rayes, B. F. (2013). Pleiotropic effects of genistein in metabolic, inflammatory, and malignant diseases. Nutr Rev, 71, 562-572.

Nairz, M., Schleicher, U., Schroll, A., Sonnweber, T., Theurl, I., Ludwiczek, S., Talasz, H., Brandacher, G., Moser, P. L., Muckenthaler, M. U., Fang, F. C., Bogdan, C., \& Weiss, G. (2013). Nitric oxidemediated regulation of ferroportin-1 controls macrophage iron homeostasis and immune function in Salmonella infection. J Exp Med, 210, 855-873.

Nemeth, E., Rivera, S., Gabayan, V., Keller, C., Taudorf, S., Pedersen, B. K., \& Ganz, T. (2004). IL-6 mediates hypoferremia of inflammation by inducing the synthesis of the iron regulatory hormone hepcidin. J Clin Invest, 113, 1271-1276. 
Nemeth, E., Tuttle, M. S., Powelson, J., Vaughn, M. B., Donovan, A., Ward, D. M., Ganz, T., \& Kaplan, J. (2004). Hepcidin regulates cellular iron efflux by binding to ferroportin and inducing its internalization. Science, 306, 2090-2093.

Nemeth, E., Valore, E. V., Territo, M., Schiller, G., Lichtenstein, A., \& Ganz, T. (2003). Hepcidin, a putative mediator of anemia of inflammation, is a type II acute-phase protein. Blood, 101, 2461-2463.

Neufeld, E. J., Galanello, R., Viprakasit, V., Aydinok, Y., Piga, A., Harmatz, P., Forni, G. L., Shah, F. T., Grace, R. F., Porter, J. B., Wood, J. C., Peppe, J., Jones, A., \& Rienhoff, H. Y., Jr. (2012). A phase 2 study of the safety, tolerability, and pharmacodynamics of FBSO701, a novel oral iron chelator, in transfusional iron overload. Blood, 119, 3263-3268.

Nohe, A., Keating, E., Knaus, P., \& Petersen, N. O. (2004). Signal transduction of bone morphogenetic protein receptors. Cell Signal, 16, 291-299.

Oliveira, S. J., de Sousa, M., \& Pinto, J. P. (2011). ER Stress and Iron Homeostasis: A New Frontier for the UPR. Biochem Res Int, 2011, 896474.

Palaneeswari, M. S., Ganesh, M., Karthikeyan, T., Devi, A. J., \& Mythili, S. V. (2013). Hepcidinminireview. J Clin Diagn Res, 7, 1767-1771.

Park, C. H., Valore, E. V., Waring, A. J., \& Ganz, T. (2001). Hepcidin, a urinary antimicrobial peptide synthesized in the liver. J Biol Chem, 276, 7806-7810.

Paya, D., Maupoil, V., Schott, C., Rochette, L., \& Stoclet, J. C. (1995). Temporal relationships between levels of circulating NO derivatives, vascular NO production and hyporeactivity to noradrenaline induced by endotoxin in rats. Cardiovasc Res, 30, 952-959.

Peters, H. P., Laarakkers, C. M., Swinkels, D. W., \& Wetzels, J. F. (2010). Serum hepcidin-25 levels in patients with chronic kidney disease are independent of glomerular filtration rate. Nephrol Dial Transplant, 25, 848-853.

Pigeon, C., Ilyin, G., Courselaud, B., Leroyer, P., Turlin, B., Brissot, P., \& Loreal, O. (2001). A new mouse liver-specific gene, encoding a protein homologous to human antimicrobial peptide hepcidin, is overexpressed during iron overload. J Biol Chem, 276, 7811-7819.

Pinto, J. P., Ribeiro, S., Pontes, H., Thowfeequ, S., Tosh, D., Carvalho, F., \& Porto, G. (2008). Erythropoietin mediates hepcidin expression in hepatocytes through EPOR signaling and regulation of C/EBPalpha. Blood, 111, 5727-5733.

Piperno, A., Galimberti, S., Mariani, R., Pelucchi, S., Ravasi, G., Lombardi, C., Bilo, G., Revera, M., Giuliano, A., Faini, A., Mainini, V., Westerman, M., Ganz, T., Valsecchi, M. G., Mancia, G., \& Parati, G. (2011). Modulation of hepcidin production during hypoxia-induced erythropoiesis in humans in vivo: data from the HIGHCARE project. Blood, 117, 2953-2959.

Poli, M., Asperti, M., Naggi, A., Campostrini, N., Girelli, D., Corbella, M., Benzi, M., Besson-Fournier, C., Coppin, H., Maccarinelli, F., Finazzi, D., \& Arosio, P. (2014). Glycol-split nonanticoagulant heparins are inhibitors of hepcidin expression in vitro and in vivo. Blood, 123, 1564-1573.

Poli, M., Girelli, D., Campostrini, N., Maccarinelli, F., Finazzi, D., Luscieti, S., Nai, A., \& Arosio, P. (2011). Heparin: a potent inhibitor of hepcidin expression in vitro and in vivo. Blood, 117, 997-1004.

Polin, V., Coriat, R., Perkins, G., Dhooge, M., Abitbol, V., Leblanc, S., Prat, F., \& Chaussade, S. (2013). Iron deficiency: from diagnosis to treatment. Dig Liver Dis, 45, 803-809.

Preza, G. C., Ruchala, P., Pinon, R., Ramos, E., Qiao, B., Peralta, M. A., Sharma, S., Waring, A., Ganz, T., \& Nemeth, E. (2011). Minihepcidins are rationally designed small peptides that mimic hepcidin activity in mice and may be useful for the treatment of iron overload. J Clin Invest, $121,4880-4888$.

Prowle, J. R., Ostland, V., Calzavacca, P., Licari, E., Ligabo, E. V., Echeverri, J. E., Bagshaw, S. M., Haase-Fielitz, A., Haase, M., Westerman, M., \& Bellomo, R. (2012). Greater increase in urinary hepcidin predicts protection from acute kidney injury after cardiopulmonary bypass. Nephrol Dial Transplant, 27, 595-602. 
Qian, Z. M., Chang, Y. Z., Leung, G., Du, J. R., Zhu, L., Wang, Q., Niu, L., Xu, Y. J., Yang, L., Ho, K. P., \& $\mathrm{Ke}, \mathrm{Y}$. (2007). Expression of ferroportin1, hephaestin and ceruloplasmin in rat heart. Biochim Biophys Acta, 1772, 527-532.

Querbes, W., Bogorad, R. L., Moslehi, J., Wong, J., Chan, A. Y., Bulgakova, E., Kuchimanchi, S., Akinc, A., Fitzgerald, K., Koteliansky, V., \& Kaelin, W. G., Jr. (2012). Treatment of erythropoietin deficiency in mice with systemically administered siRNA. Blood, 120, 1916-1922.

Rajsheker, S., Manka, D., Blomkalns, A. L., Chatterjee, T. K., Stoll, L. L., \& Weintraub, N. L. (2010). Crosstalk between perivascular adipose tissue and blood vessels. Curr Opin Pharmacol, 10, 191-196.

Ramm, G. A., \& Ruddell, R. G. (2010). Iron homeostasis, hepatocellular injury, and fibrogenesis in hemochromatosis: the role of inflammation in a noninflammatory liver disease. Semin Liver Dis, 30, 271-287.

Ramos, E., Ruchala, P., Goodnough, J. B., Kautz, L., Preza, G. C., Nemeth, E., \& Ganz, T. (2012). Minihepcidins prevent iron overload in a hepcidin-deficient mouse model of severe hemochromatosis. Blood, 120, 3829-3836.

Rehman, A. A., Ahsan, H., \& Khan, F. H. (2013). alpha-2-Macroglobulin: a physiological guardian. J Cell Physiol, 228, 1665-1675.

Riganti, C., Campia, I., Kopecka, J., Gazzano, E., Doublier, S., Aldieri, E., Bosia, A., \& Ghigo, D. (2011). Pleiotropic effects of cardioactive glycosides. Curr Med Chem, 18, 872-885.

Rochette, L., Cottin, Y., Zeller, M., \& Vergely, C. (2013). Carbon monoxide: mechanisms of action and potential clinical implications. Pharmacol Ther, 137, 133-152.

Rochette, L., Tatou, E., Maupoil, V., Zeller, M., Cottin, Y., Jazayeri, S., Brenot, R., Girard, C., David, M., \& Vergely, C. (2011). Atrial and vascular oxidative stress in patients with heart failure. Cell Physiol Biochem, 27, 497-502.

Saeed, O., Otsuka, F., Polavarapu, R., Karmali, V., Weiss, D., Davis, T., Rostad, B., Pachura, K., Adams, L., Elliott, J., Taylor, W. R., Narula, J., Kolodgie, F., Virmani, R., Hong, C. C., \& Finn, A. V. (2012). Pharmacological suppression of hepcidin increases macrophage cholesterol efflux and reduces foam cell formation and atherosclerosis. Arterioscler Thromb Vasc Biol, 32, 299307.

Sasu, B. J., Cooke, K. S., Arvedson, T. L., Plewa, C., Ellison, A. R., Sheng, J., Winters, A., Juan, T., Li, H., Begley, C. G., \& Molineux, G. (2010). Antihepcidin antibody treatment modulates iron metabolism and is effective in a mouse model of inflammation-induced anemia. Blood, 115, 3616-3624.

Schmidt, P. J., Toudjarska, I., Sendamarai, A. K., Racie, T., Milstein, S., Bettencourt, B. R., Hettinger, J., Bumcrot, D., \& Fleming, M. D. (2013). An RNAi therapeutic targeting Tmprss6 decreases iron overload in $\mathrm{Hfe}(-/-)$ mice and ameliorates anemia and iron overload in murine betathalassemia intermedia. Blood, 121, 1200-1208.

Schroeder, S. E., Reddy, M. B., \& Schalinske, K. L. (2007). Retinoic acid modulates hepatic iron homeostasis in rats by attenuating the RNA-binding activity of iron regulatory proteins. $J$ Nutr, 137, 2686-2690.

Schubert, T. E., Bosserhoff, A. K., Peyssonaux, C., Echtenacher, B., Knutson, M., Hofstadter, F., \& Mannel, D. N. (2012). Hypoferraemia during the early inflammatory response is dependent on tumour necrosis factor activity in a murine model of protracted peritonitis. Mol Med Rep, $6,838-842$.

Schwarz, P., Kubler, J. A., Strnad, P., Muller, K., Barth, T. F., Gerloff, A., Feick, P., Peyssonnaux, C., Vaulont, S., Adler, G., \& Kulaksiz, H. (2012). Hepcidin is localised in gastric parietal cells, regulates acid secretion and is induced by Helicobacter pylori infection. Gut, 61, 193-201.

Schwoebel, F., van Eijk, L. T., Zboralski, D., Sell, S., Buchner, K., Maasch, C., Purschke, W. G., Humphrey, M., Zollner, S., Eulberg, D., Morich, F., Pickkers, P., \& Klussmann, S. (2013). The effects of the anti-hepcidin Spiegelmer NOX-H94 on inflammation-induced anemia in cynomolgus monkeys. Blood, 121, 2311-2315. 
Shin, D. Y., Chung, J., Joe, Y., Pae, H. O., Chang, K. C., Cho, G. J., Ryter, S. W., \& Chung, H. T. (2012). Pretreatment with CO-releasing molecules suppresses hepcidin expression during inflammation and endoplasmic reticulum stress through inhibition of the STAT3 and CREBH pathways. Blood, 119, 2523-2532.

Sicard, P., Acar, N., Gregoire, S., Lauzier, B., Bron, A. M., Creuzot-Garcher, C., Bretillon, L., Vergely, C., \& Rochette, L. (2007). Influence of rosuvastatin on the NAD(P)H oxidase activity in the retina and electroretinographic response of spontaneously hypertensive rats. $\mathrm{Br} J$ Pharmacol, 151, 979-986.

Sicard, P., Delemasure, S., Korandji, C., Grand, A. S. L., Lauzier, B., Guilland, J. C., Duvillard, L., Zeller, M., Cottin, Y., Vergely, C., \& Rochette, L. (2008). Anti-hypertensive effects of Rosuvastatin are associated with decreased inflammation and oxidative stress markers in hypertensive rats. Free Radical Research, 42, 226-236.

Silvestri, L., Pagani, A., \& Camaschella, C. (2008). Furin-mediated release of soluble hemojuvelin: a new link between hypoxia and iron homeostasis. Blood, 111, 924-931.

Sow, F. B., Nandakumar, S., Velu, V., Kellar, K. L., Schlesinger, L. S., Amara, R. R., Lafuse, W. P., Shinnick, T. M., \& Sable, S. B. (2011). Mycobacterium tuberculosis components stimulate production of the antimicrobial peptide hepcidin. Tuberculosis (Edinb), 91, 314-321.

Straub, A. C., Lohman, A. W., Billaud, M., Johnstone, S. R., Dwyer, S. T., Lee, M. Y., Bortz, P. S., Best, A. K., Columbus, L., Gaston, B., \& Isakson, B. E. (2012). Endothelial cell expression of haemoglobin alpha regulates nitric oxide signalling. Nature, 491, 473-477.

Strnad, P., Schwarz, P., Rasenack, M. C., Kucukoglu, O., Habib, R. I., Heuberger, D., Ehehalt, R., Muller, M. W., Stiehl, A., Adler, G., \& Kulaksiz, H. (2011). Hepcidin is an antibacterial, stress-inducible peptide of the biliary system. PLoS One, 6, e16454.

Sullivan, J. L. (2007). Macrophage iron, hepcidin, and atherosclerotic plaque stability. Exp Biol Med (Maywood), 232, 1014-1020.

Sun, C. C., Vaja, V., Chen, S., Theurl, I., Stepanek, A., Brown, D. E., Cappellini, M. D., Weiss, G., Hong, C. C., Lin, H. Y., \& Babitt, J. L. (2013). A hepcidin lowering agent mobilizes iron for incorporation into red blood cells in an adenine-induced kidney disease model of anemia in rats. Nephrol Dial Transplant, 28, 1733-1743.

Tanno, T., Bhanu, N. V., Oneal, P. A., Goh, S. H., Staker, P., Lee, Y. T., Moroney, J. W., Reed, C. H., Luban, N. L., Wang, R. H., Eling, T. E., Childs, R., Ganz, T., Leitman, S. F., Fucharoen, S., \& Miller, J. L. (2007). High levels of GDF15 in thalassemia suppress expression of the iron regulatory protein hepcidin. Nat Med, 13, 1096-1101.

Tanno, T., Noel, P., \& Miller, J. L. (2010). Growth differentiation factor 15 in erythroid health and disease. Curr Opin Hematol, 17, 184-190.

Tanno, T., Porayette, P., Sripichai, O., Noh, S. J., Byrnes, C., Bhupatiraju, A., Lee, Y. T., Goodnough, J. B., Harandi, O., Ganz, T., Paulson, R. F., \& Miller, J. L. (2009). Identification of TWSG1 as a second novel erythroid regulator of hepcidin expression in murine and human cells. Blood, 114, 181-186.

Theurl, I., Schroll, A., Sonnweber, T., Nairz, M., Theurl, M., Willenbacher, W., Eller, K., Wolf, D., Seifert, M., Sun, C. C., Babitt, J. L., Hong, C. C., Menhall, T., Gearing, P., Lin, H. Y., \& Weiss, G. (2011). Pharmacologic inhibition of hepcidin expression reverses anemia of chronic inflammation in rats. Blood, 118, 4977-4984.

Theurl, I., Theurl, M., Seifert, M., Mair, S., Nairz, M., Rumpold, H., Zoller, H., Bellmann-Weiler, R., Niederegger, H., Talasz, H., \& Weiss, G. (2008). Autocrine formation of hepcidin induces iron retention in human monocytes. Blood, 111, 2392-2399.

Troutt, J. S., Butterfield, A. M., \& Konrad, R. J. (2013). Hepcidin-25 concentrations are markedly increased in patients with chronic kidney disease and are inversely correlated with estimated glomerular filtration rates. J Clin Lab Anal, 27, 504-510.

Tsuji, Y. (2005). JunD activates transcription of the human ferritin $\mathrm{H}$ gene through an antioxidant response element during oxidative stress. Oncogene, 24, 7567-7578. 
Tuomainen, T. P., Punnonen, K., Nyyssonen, K., \& Salonen, J. T. (1998). Association between body iron stores and the risk of acute myocardial infarction in men. Circulation, 97, 1461-1466.

van Rhee, F., Fayad, L., Voorhees, P., Furman, R., Lonial, S., Borghaei, H., Sokol, L., Crawford, J., Cornfeld, M., Qi, M., Qin, X., Herring, J., Casper, C., \& Kurzrock, R. (2010). Siltuximab, a novel anti-interleukin-6 monoclonal antibody, for Castleman's disease. J Clin Oncol, 28, 3701-3708.

Vecchi, C., Montosi, G., Zhang, K., Lamberti, I., Duncan, S. A., Kaufman, R. J., \& Pietrangelo, A. (2009). ER stress controls iron metabolism through induction of hepcidin. Science, 325, 877-880.

Verga Falzacappa, M. V., \& Muckenthaler, M. U. (2005). Hepcidin: iron-hormone and anti-microbial peptide. Gene, 364, 37-44.

Vujic, M. (2014). Molecular basis of HFE-hemochromatosis. Front Pharmacol, 5, 42.

Vuppalanchi, R., Troutt, J. S., Konrad, R. J., Ghabril, M., Saxena, R., Bell, L. N., Kowdley, K. V., \& Chalasani, N. (2014). Serum hepcidin levels are associated with obesity but not liver disease. Obesity (Silver Spring), 22, 836-841.

Waldvogel-Abramowski, S., Waeber, G., Gassner, C., Buser, A., Frey, B. M., Favrat, B., \& Tissot, J. D. (2014). Physiology of iron metabolism. Transfus Med Hemother, 41, 213-221.

Wang, H., Dong, J., Zuo, L., Liu, J., Zhu, W., Li, Y., Gu, L., Zhao, J., Zhang, L., Gong, J., Zhang, W., Li, N., \& Li, J. (2014). Anti-mouse CD52 monoclonal antibody ameliorates iron-deficient anaemia in IL-10 knockout mice. Br J Nutr, 111, 987-995.

Ward, D. G., Roberts, K., Brookes, M. J., Joy, H., Martin, A., Ismail, T., Spychal, R., Iqbal, T., \& Tselepis, C. (2008). Increased hepcidin expression in colorectal carcinogenesis. World J Gastroenterol, $14,1339-1345$.

Wood, M. J., Gadd, V. L., Powell, L. W., Ramm, G. A., \& Clouston, A. D. (2014). Ductular reaction in hereditary hemochromatosis: the link between hepatocyte senescence and fibrosis progression. Hepatology, 59, 848-857.

Yin, S., Wang, Z., \& Bernstein, E. R. (2013). Formaldehyde and methanol formation from reaction of carbon monoxide and hydrogen on neutral Fe2S2 clusters in the gas phase. Phys Chem Chem Phys, 15, 4699-4706.

Yu, P. B., Hong, C. C., Sachidanandan, C., Babitt, J. L., Deng, D. Y., Hoyng, S. A., Lin, H. Y., Bloch, K. D., \& Peterson, R. T. (2008). Dorsomorphin inhibits BMP signals required for embryogenesis and iron metabolism. Nat Chem Biol, 4, 33-41.

Yuan, X. M., \& Li, W. (2003). The iron hypothesis of atherosclerosis and its clinical impact. Ann Med, $35,578-591$.

Zhang, L., Lu, D., Zhang, W., Quan, X., Dong, W., \& Xu, Y. (2012). Cardioprotection by Hepc1 in $\mathrm{CTnT}(\mathrm{R} 141 \mathrm{~W})$ transgenic mice. Transgenic Res, 21, 867-878.

Zhen, A. W., Nguyen, N. H., Gibert, Y., Motola, S., Buckett, P., Wessling-Resnick, M., Fraenkel, E., \& Fraenkel, P. G. (2013). The small molecule, genistein, increases hepcidin expression in human hepatocytes. Hepatology, 58, 1315-1325. 
Figure 1: Regulation of systemic iron metabolism and hepcidin expression.

Enterocytes incorporate iron via divalent metal transporter 1(DMT1) located on the apical membrane upon reduction of $\mathrm{Fe} 3+$ to $\mathrm{Fe} 2+$ by ferri-reductase. Hepatic hepcidin regulates the efflux of iron from the cells by regulating the activity of ferroportin (FPN). The synthesis and secretion of hepcidin by hepatocytes are influenced by iron levels in relationship with infection and inflammation. Hepcidin preferentially binds to the blood glycoprotein, activated $\alpha 2$-macroglobulin $(\alpha 2 \mathrm{M})$. Macrophages and spleen recognize damaged or senescent erythrocytes, phagocytize them and digest them to extract heme and iron. Heme is degraded through the action of heme oxygenase-1 (HO-1) to release iron. Macrophages export $\mathrm{Fe}^{2+}$ via FPN, in a process coupled by re-oxidation of $\mathrm{Fe}^{2+}$ to $\mathrm{Fe}^{3+}$. Hephaestin, assists by converting $\mathrm{Fe}^{2+}$ to $\mathrm{Fe}^{3+}$ which is then bound by transferrin (Tf). In the circulation, iron is bound to Tf. Tf possesses receptors (TfR) that mediate iron metabolism.

Figure 2: Hepcidin: the amino-acid sequence and structure.

Hepcidin is synthesized as an 84-amino-acid (AA) preproprotein. A furin-like proprotein convertase is responsible for cleavage of prohepcidin to hepcidin. The human 25-amino-acid hepcidin peptide contains four disulphide bonds. N-terminal domain interacts with ferroportin.

Figure 3: Histology: Hepcidin expression in the liver and heart.

Representative images of hepcidin-25 immunostained liver and heart sections.

"After fixation in formalin and dehydration in alcohol, the samples were embedded in paraffin. Slices of $5 \mu \mathrm{m}$ were cut and immunostained for hepcidin. Briefly, after antigen retrieval (citrate buffer pH6), slices were incubated with $\mathrm{H}_{2} \mathrm{O}_{2} 3 \%$ in TBST ( $2 \times 8$ minutes) and saturated (Impress Kit serum plus BSA 3\% in TBST) for 20 minutes. They were incubated with anti-hepcidin (1/50, Abcam - ab30760) overnight at $4^{\circ} \mathrm{C}$. After 3 rinses in TBST, the slices were incubated with Impress Kit Solution (Vector Lab - MP7401) for 30 minutes. After the revelation step with Nova Red kit (Vector Lab - SK4800), they were counterstained in hematoxylin." 
Figure 4: Human ferroportin and functional domains (12 transmembrane regions that were 21-23 amino acids long).

Hepcidin binds to a domain on an extracellular loop of ferroportin. Hepcidin exerts its influence on iron metabolism via down-regulation of FPN-mediated iron export. Janus kinase 2 (JAK2) binds to a cytoplasmic domain of ferroportin.

Figure 5: Expression of hepcidin in hepatocyte and macrophages in response to iron signal and targeting of the hepcidin-ferroportin axis for human therapy.

Hepcidin gene expression is up-regulated by inflammation and iron through the JAK/STAT and $B M P / S M A D$ pathways respectively. The BMP- 6 signal acts through its receptor (BMPR), and is modulated by hemojuvelin (HJV). TMPRSS6 cleaves membrane-bound HJV. BMPs can also signal through SMAD-independent pathways, notably via MAP kinases. Dorsomorphin inhibits BMP signaling through the SMAD pathway. SMAD complexes bind to BMPresponsive elements (BMP-Res). TNF, pathogens and IL-6 stimulate hepcidin synthesis via STAT-3 activation. The P38, MAP-kinase and ERK 1-2 pathways are activated in response of iron signals.

Diferric transferrin (Tf) binds to TF-Receptor 1 (TfR-1) on the cell surface and the complex undergoes endocytosis. HFE is a protein that competes with Tf for binding to TFR1. TLR signalling requires interactions of the receptor domains of the receptor and adaptor proteins.

Hepcidin expression in macrophages is regulated mainly through TLR4 receptors associated with adaptor proteins (TRAM, TRIF, MAL, MyD88). Hepcidin mRNA expression in macrophages induced by LPS or HMGB1 depends on $\mathrm{NF}_{\mathrm{k}} \mathrm{B}$.

For simplicity, not all factors involved with expression are described in this Figure. Pharmacological options (shaded parts).

BMP-RE: Bone Morphogenetic Protein-Responsive Element; Hepcidin gene (HAMP, 19q13) HAMP: The HAMP (present in Histidine kinases, Adenylate cyclases, Methyl accepting proteins and Phosphatases) 
Table 1. Direct and indirect Hepcidin agonists and antagonists.

\section{Direct and indirect Hepcidin agonists}

\begin{tabular}{|l|l|}
\hline $\begin{array}{l}\text { Minihepcidin } \\
\text { P65 }\end{array}$ \\
$\begin{array}{l}\text { Monoclonal antibodies } \\
\text { LY2787106 }\end{array}$ \\
$\begin{array}{l}\text { Serine protease } \\
\text { TMPRSS6 }\end{array}$ \\
$\begin{array}{l}\text { BMP6 analogues } \\
\text { Genistein }\end{array}$ \\
$\begin{array}{l}\text { Spiegelmers } \\
\text { NOX-H94 } \\
\text { NOX-H94002 }\end{array}$ \\
PRS-080 \\
PRS-110
\end{tabular}




\section{Inhibitors of Hepcidin production}

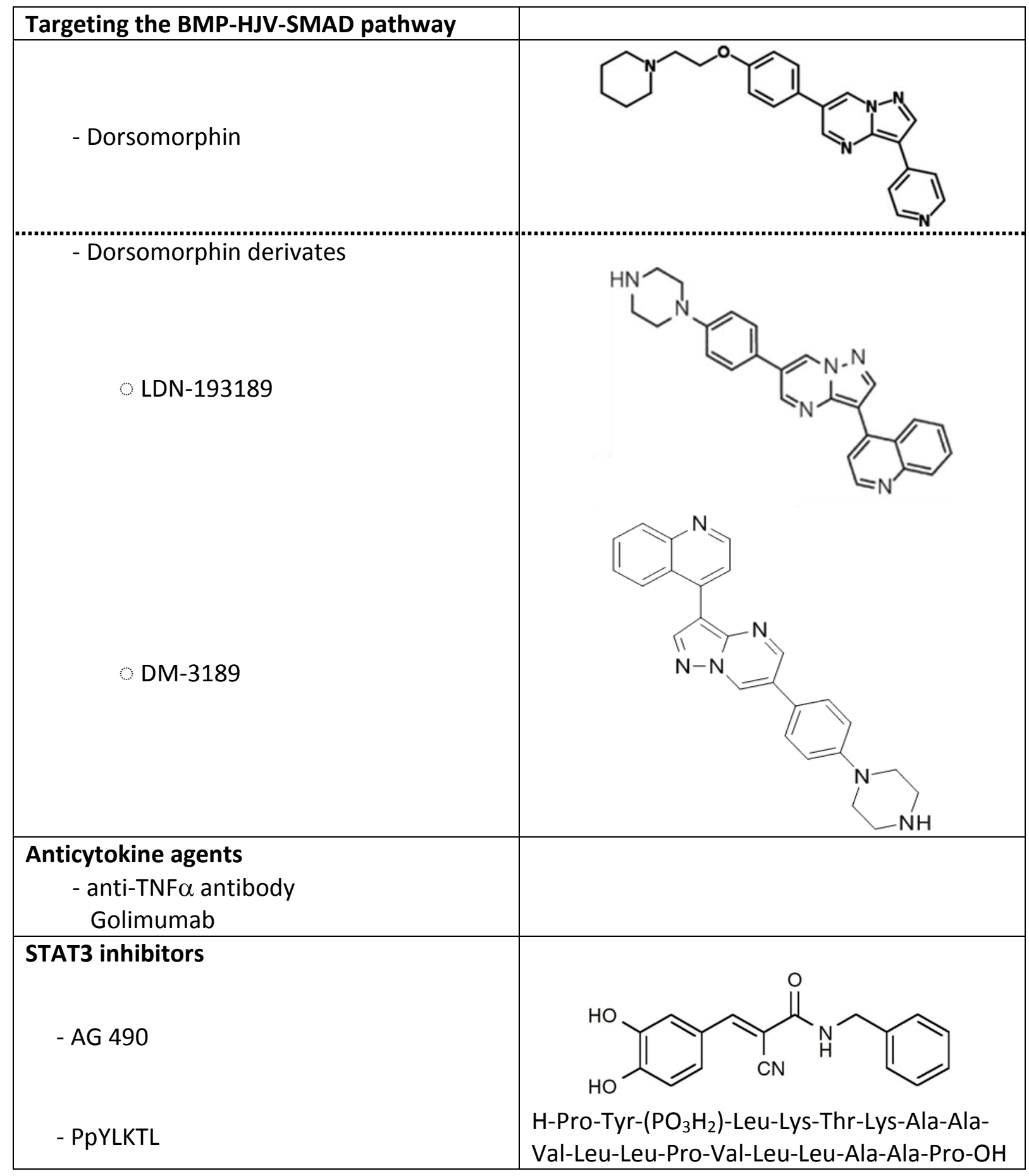


Pharmacological compounds with Hepcidin antagonistic properties

Fursultiamin
Pyrithione zinc
Vitamin $\mathrm{C}$
Vitamin $\mathrm{A}$
Sitamin $\mathrm{D}$

